\title{
266 Fuzzy front-end studies: current state and future directions for new product development
}

\author{
Dongmyung Park ${ }^{1}$ (D ) Ji Han ${ }^{2} \cdot$ Peter R. N. Childs ${ }^{1}$
}

Received: 13 June 2020 / Revised: 29 March 2021 / Accepted: 3 April 2021 / Published online: 19 April 2021

(c) The Author(s) 2021

\begin{abstract}
266 fuzzy front-end (FFE) studies in the new product development (NPD) sector were examined. The studies were selected using a bibliometrics method, and chronologically and statistically examined with ten criteria divided into two dimensions. The first dimension is associated with overall attributes of the FFE, consisting of six criteria: the study taxonomy, model type, NPD speed, NPD attributes, model characteristic, and model structure. The second dimension is relevant to the FFE performance structure related to process parameters, comprised of four criteria: the FFE task, activity, performance method, and toolkit. In terms of those two dimensions, the paper looks at previous FFE studies to gain an understanding of features of each FFE study along with related knowledge and theories, as well as identification of evolution trends of FFE studies. Based on the identification, an FFE model development strategy for each criterion is formulated, and this paper proposes possible options for executing those strategies which exert influence on the form of the cluster network. The intention is for the database to be utilised as an overview of all existing FFE studies and allow specific FFE studies to be selected to examine FFE approaches.This paper provides FFE model development guidance on how to deal with the overall attributes and outcomes of the FFE which affect the entirety of the innovation process, and how to manage the performance structure related to process parameters.
\end{abstract}

Keywords Design $\cdot$ Product $\cdot$ Development $\cdot$ Fuzzy front end $\cdot$ Innovation strategy $\cdot$ Management

\section{Research background and motivation}

Researchers have dedicated substantial attention to developing a number of product innovation processes also known as New Product Development (NPD) processes and product design processes ${ }^{1}$ ( Wynn and Clarkson 2018), with more than 600 processes reported (Simms 2012; Reim et al. 2015). The innovation process particularly has challenges to both develop and manage continuously (Wynn and Clarkson 2018). The need to improve the product innovation process

Dongmyung Park

d.park14@imperial.ac.uk

Ji Han

ji.han@liverpool.ac.uk

Peter R. N. Childs

p.childs@imperial.ac.uk

1 Dyson School of Design Engineering, Imperial College London, South Kensington, London SW7 2DB, UK

2 Division of Industrial Design, University of Liverpool, Brownlow Hill, Liverpool L69 3GH, UK has been recognised as a critical issue in both academic and industrial research circles (Cross 1993; Salerno et al. 2015; Tzortzopoulo et al. 2006), and studies on the product innovation process are becoming increasingly specific (Gurtner and Reinhardt 2016).

The fuzzy front end (FFE) is an initial component of the product innovation process (Achiche et al. 2013; Carbone and Tippett 2014; Stevens and Burley 2003) and is acknowledged as the most important part (Eling et al. 2014; Evanschitzky et al. 2012). There are two main factors for this: (1) more than $60 \%$ of NPD-related parameters are set up in this initial design phase (Chang et al. 2007; Talke et al. 2006; Williams et al. 2007), and thus, a significant proportion of an NPD project's time and cost are committed (Achiche

1 This study dealt with studies which limit to the consumer product sector among various NPD domains. It does not involve intangible developments such as the service design, branding, or social innovation aspect, but it does concentrate on tangible artefacts such as consumer products, electronics, medica devices, vehicles, furniture, and so on. The NPD domain excludes pharmaceuticals and microchips. The attributes, characteristics, and features of these product types are different from those of products covered by this study, meaning that their development courses and models are naturally different. 
et al. 2013; Bacciotti et al. 2016; Koen et al. 2002; Reid and Brentani 2004; Verworn et al., 2008); (2) the overall attributes and outcomes of the FFE affect the entirety of the product innovation process (Achiche et al. 2013; Bacciotti et al. 2016; Kim and Wilemon 2002a; Thanasopon et al. 2016). Nonetheless, this initial design phase is viewed as a vulnerability in the whole course of the product innovation process due to the high probability of encountering difficulties in dealing with those two factors (Brun and Saetre 2008; Frishammar et al. 2011). The difficulties are triggered by uncertainty and ambiguity inherent in the FFE (Brun and Saetre 2008; Frishammar et al. 2011).

Hence, efforts to understand the FFE in-depth have been made (Kock et al. 2015; Markham, 2013; Yoon and Jetter 2015). With an attention devoted to the different FFE topics, there has been an increase in the volume of studies developing many processes, models, or frameworks. Studies conducted by Costa and Toledo (2016) and Takey and Carvalho (2016) reviewed many studies which have made a contribution on the FFE sector. Ottum and Moore (1997) proposed a framework to examine the relationship between marketled information processing and new product financial success. Khurana and Rosenthal (1998) offered a holistic FFE framework which reflects links between business strategy and NPD; between individual NPD projects and an overall development portfolio; between core teams and executive committees. Langerak et al. (2004) devised a conceptual model to specify the relationship between market orientation, NPD performance, and organisational performance that is mediated by FFE activities. Chen and Gao (2005) developed a conceptual model in the complex product system context, in which FFE fuzziness, activities, and organisational elements are extrinsic variables, FFE performance is the mediating variable, and NPD performance is an intrinsic variable. Zhang and Doll (2011) developed a relationship framework, as a casual model, in which fuzziness in the front-end part and foundation elements are external variables, team vision is the mediate variable, and NPD performance is an internal variable. Verworn and Herstatt (1999) and Verworn et al. (2008) suggested a conceptual framework to examine the relationship between three-dimensional FFE factors which indicates reduction of market and technical uncertainty, intensity of planning, and NPD performance. Yu et al. (2006) concentrated on the effect of ideation on NPD performance during the FFE. Brun and Saetre (2008) and Brun et al. (2009) studied the classification of ambiguity in NPD and reduction of ambiguity in NPD projects. Achiche et al. (2013), Ester and Daniel (2007), Kim and Wilemon (2010), and Koen et al. (2002) proposed methods to execute the FFE.

However, few models shed light on (1) which overall attributes are appropriate for this early design phase and (2) how the FFE truly deals with the performance structure relevant to processing parameters: this is related to the two main rationales which make the FFE the weakest as well as the crucial component of the product innovation process. Therefore, the development of FFE models which deal with those two factors are needed.

This study aims to propose strategies for new FFE model development considering those two factors which make the FFE crucial but vulnerable; (1) overall attributes of the FFE: the study taxonomy, model type, NPD speed, NPD attributes, model characteristic, and model structure and (2) the FFE performance structure related to processing parameters: the FFE task, activity, performance method, and toolkit. The strategies were inferred through an examination of a diverse range of FFE studies in NPD domains. A total of 266 FFE studies were gathered using a "Bibliometrics" method, and these studies were chronologically and statistically examined using appraisal criteria. The examination supported gaining an understanding of the features of each FFE study and relevant knowledge and theories, as well as historical trends of FFE study evolution and their proportions. The intention of this paper is for inferring new FFE model development directions. Also, the subsequent product of this paper can be utilised as a database that allows specific FFE studies to be selected and which enables an overview of the existing FFE studies: indeed, contrary to the existence of many studies on the wider product innovation processes, there are few studies intensively focusing on investigating the FFE component.

The remainder of this paper consists, first of a research methodology framed in terms of establishing new FFE model development strategies. Section 3 addresses knowledge, theories, and historical trends of FFE model development and their proportions for each criterion. Section 4 discusses new strategies for FFE model development. The final section concludes this study with a summary of the paper and envisages the expected contributions.

\section{Research design and methods}

\subsection{Research framework}

An overall research framework has been adopted from the approach devised by van Aken (2005) to build the holistic structure of this study. According to van Aken's study, the development of the innovation process in NPD domains means coming up with an "Optimum Solution", the best development and management platform for artefacts, fitting the "Best Requirements" inferred from "Various Ranges of Solution Concepts" which are themselves derived from "Past to State-of-the-Art" processes.

Based on this approach, as shown in Fig. 1, 266 FFE studies were selected from both the academic and industrial bodies of literature, arranged in chronological order to 


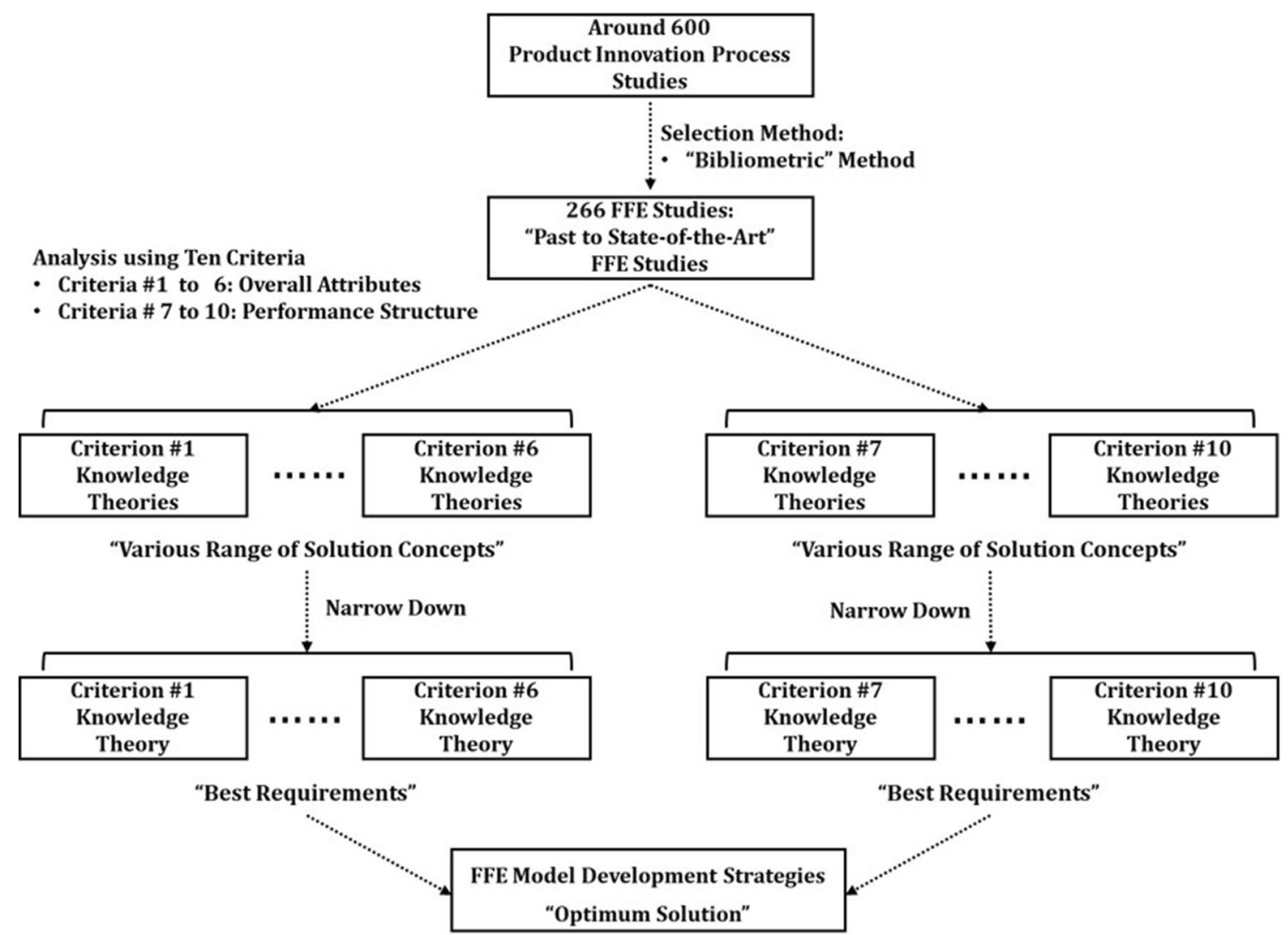

Fig. 1 Overall research framework

grasp "Past to State-of-the-Art" FFE studies. The 266 studies were analysed using particular criteria concerning (1) overall attributes of the FFE and (2) the FFE performance structure relevant to processing parameters. The analysis is to figure out features of each FFE study and associated knowledge and theories, and historical trends of FFE model development and their proportions, as "Various Ranges of Solution Concepts". Based on the results, strategies for a new FFE model development were clarified by narrowing the "Various Ranges of Solution Concepts" down to "Best Requirements", and finally the "Optimum Solution".

\subsection{Data collection method}

\subsubsection{Taxonomy of the subjects of the FFE studies}

A total of ten criteria were derived, based on the suggestion by Mendes and Oliveira (2015) and Oliveira and Rozenfeld (2010). Their studies which classified FFE studies into four groups have a proven track record of classification system in FFE studies.

1. Independent FFE model: FFE studies providing models developed for the front-end part only were covered in this classification. Partial FFE models devised solely for one or two front-end tasks, e.g., an opportunity identification, ideation, and conceptual design.

2. Dependent FFE model: FFE studies offering models which are part of wider parts covering the product innovation process in general were also incorporated into this examination. General innovation processes by targeting the first section were included, since most innovation processes have the FFE component at the head of the process.

3. Study on the FFE issue: FFE studies which do not provide any model types but are related to FFE issues, e.g., its attributes, roles, and functions.

4. Study related to the FFE issue: studies which do not directly target the FFE but are indirectly related to the FFE issues and whose knowledge and theories may be relevant in the new FFE model development were also included, e.g., information processing, knowledge accumulation, decision-making processing, and trend forecasting. 


\subsubsection{Process by which to gather FFE studies}

Studies which conducted surveys concerning different studies were referenced to support design a protocol to collect studies used in this study. The study conducted by Mendes and Oliveira (2015) is a seminal work in this field, which carried out a systematic literature review, a method which has been highlighted in the social science and engineering design domains in recent years (Cook et al. 1997; Reim et al. 2015). "Bibliometrics" (De Bellis 2009; Okubo 1997; Ramos-Rodríguez and Ruíz-Navarro 2004) focusing on the most cited papers, papers affecting the most cited papers, the most cited authors, and the most highly mentioned keywords, ${ }^{2}$ which carries out statistical and quantitative interpretations of data, was utilised in this study. Also, another remarkable note was whether those studies were published by top influential academic journal organisations (Baumgartner and Pieters 2003; Biemans et al. 2007; Durisin et al. 2010). The 'Web of Science' database used for this investigation (Carvalho et al. 2013; Mendes and Oliveira 2015). In this way, the data, FFE studies conducted from early 1900 s to late 2020 s, were gathered.

Figure 2 depicts the overall taxonomy and collection process. By classification and systematic selection of usable studies, this study endeavoured not only to maximise scientific rigour, validity, and reliability but also to minimise bias in the gathering and screening of FFE studies. The inferences drawn from this eight-step process can be classified into two sections, connoting different development directions of a new FFE model.

The first section includes the most cited studies found in Steps 1 and 3, and the most prominent studies as determined by a majority of experts, identified in Step 5. The analysis of those models can provide basic insights into the development of a new FFE model.

The second section covers the remaining studies attained during Steps 2, 4, 6, and 7. Most of the studies were gathered from additional articles referenced in the original studies investigated in Steps 1, 3, and 5. Even though these remaining studies are weaker in their representativeness, each study has its own characteristics in terms of attributes, structure, and operations. These steps help to prevent underestimation of parts which are easy to miss, which can affect a more

\footnotetext{
2 The keywords used were defined with the following two dimensions. The former includes fuzzy front end, new product development, and product innovation, from the comprehensive aspect. From the specific aspect, the latter covers corresponding words to ten criteria established in this study, e.g., FFE model, design process, as well as FFE issues, e.g., FFE uncertainty and ambiguity, FFE information processing, and FFE knowledge accumulation. Each keyword was used as the search string manifoldly when inputted in the search engine.
}

elaborate model development. As a result, knowledge and theories gained from those steps may have great value in analyses looking at deep-rooted development. It can also be useful in the design of an entirely new model, contrary to concentrating on the most representative studies which leads to a clustering of outcomes with the majority of studies looking at the similar data.

When selecting FFE studies, the guiding principle concentrated on the latest version of a study that has continuously evolved over many years. For instance, the FFE study developed by Verworn and Herstatt (2003) and Verworn (2009) was examined, focusing on the version from 2009. However, when the initial version of a study has a broader representation, the investigation instead looked at the earliest version. For example, in the case of the study by Cooper and Cooper et al. from 1988 to 2018, the analysis depended upon the 1988 version as the cornerstone of the whole range of studies.

To screen out less relevant studies, a filtering progress was adopted from the study by Mendes and Oliveira (2015). The process adopted began in the early phases, as soon as the first ten papers were validated. It involved five scholars comparing their decisions on the publications. Intense discussions were held over five meetings to arrive at a consensus on the judgement. After an agreement was reached, seven papers out of those initial ten were adopted, and the remaining three dropped. This method was utilised to screen subsequent tranches of potential studies until additional 259 papers were finally included, resulting in the 266 studies which this study ultimately uses. When studies had very little to do with the FFE or when they focused on very diverse areas despite having FFE as one of their main keywords (focus missing), e.g., FFE studies handles the latter part of the NPD process more than its initial part, or when studies only tangentially relevant to the domains of this examination (out of scope), e.g., the aim of the FFE studies is supporting the development of pharmaceuticals or microchips, these studies were excluded. Also, duplicated studies were excluded at every step.

\subsection{Data analysis method}

\subsubsection{Establishment of appraisal criteria}

As shown in the Imperial College London (ICL) Research Data Repository (URL: http://doi.org/10.14469/hpc/ 7725), a total of ten criteria were derived, divided into two dimensions. The former dimension is associated with overall attributes of FFE, consisting of six criteria (Criteria 1-6): the study taxonomy, model type, NPD speed, NPD attributes, model characteristic, and model structure. The latter dimension is relevant to the FFE performance structure which relates to processing parameters, 


\section{Taxonomy of the Subjects of FFE Studies}

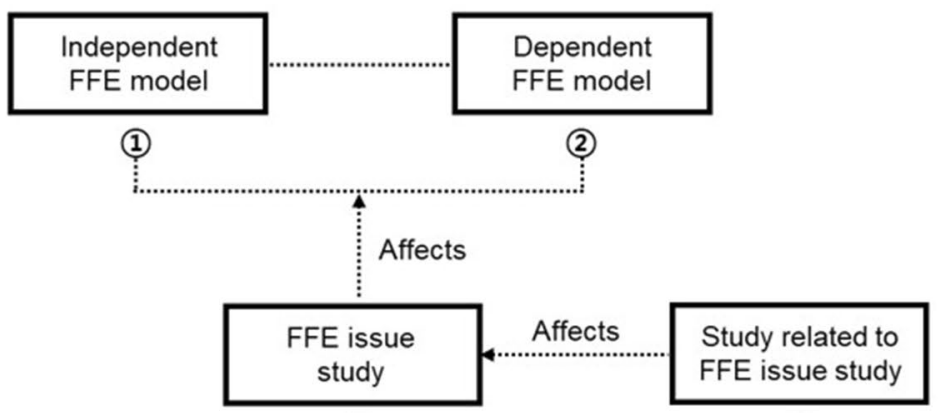

(3)

(4)

\section{Process to Select FFE Studies}

\section{Process to Select FFE Studies \\ to Select and Filter Study
Taxonomy of the Subjects of FFE Studies

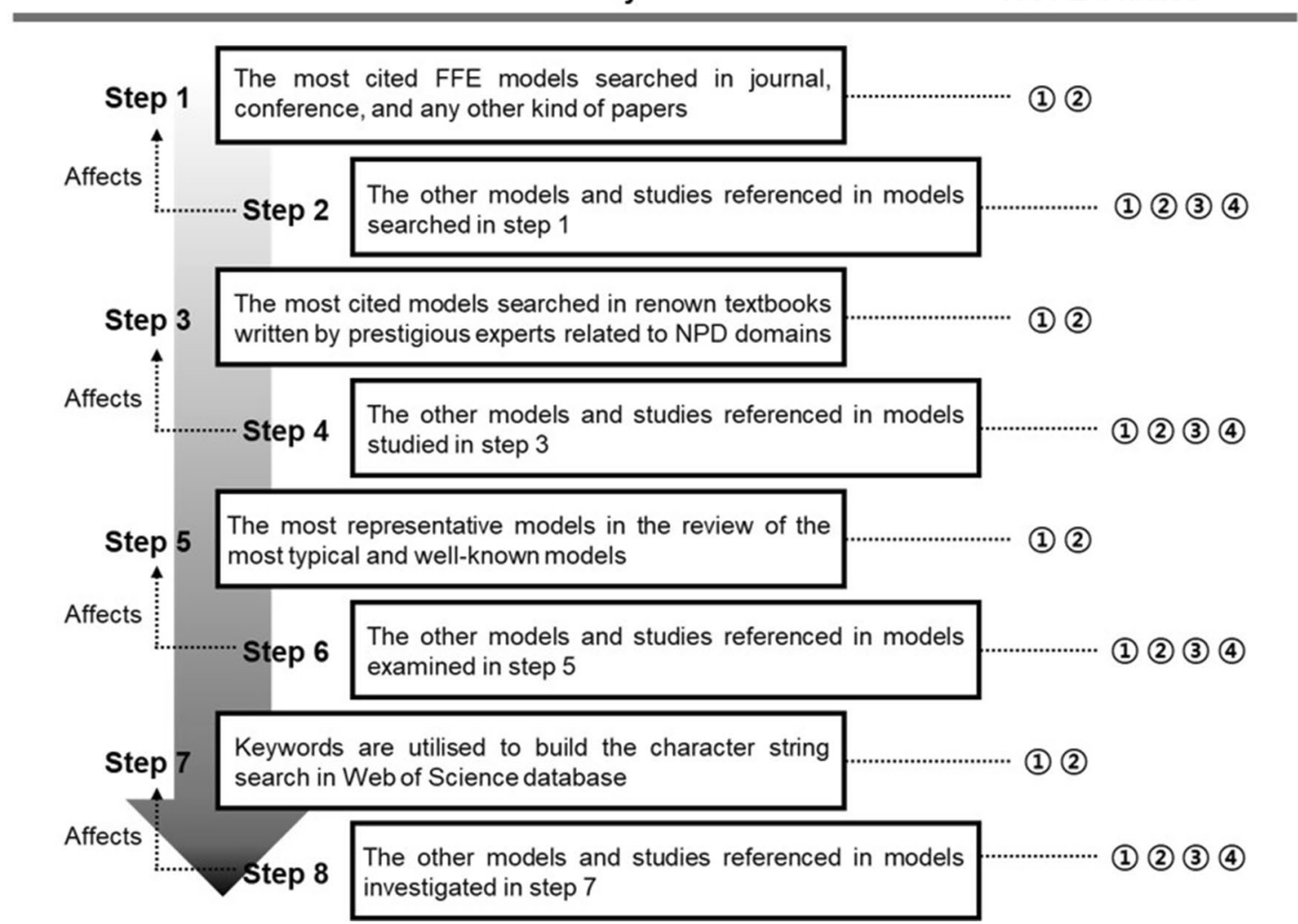

Fig. 2 Overall model selection protocol

comprised of four criteria (Criteria 7-10): the FFE task, activity, performance method, and toolkit. Criteria associated with the overall attributes of the FFE, frequently defined in recent conferences, such as the International Design Conference 2018, the International Conference on Engineering Design (ICED) 2019, and CIRP Design 2020 were set up. For appraisal criteria 7-10, units of the FFE performance structure, the basic constituents making up the structure of the model, were defined by studies (Birkhofer et al. 2002; Herstatt and Verworn 2001; McCarthy et al. 2006; van Aken 2005). To create the most optimal demands for developing a new FFE model in which the broadest and deepest range of development requirements are reflected (Williams et al. 2007), those criteria established were concrete in greater detail. 
Table 1 Inter-rater agreement between the analyses of the author and the participants

\begin{tabular}{lll}
\hline Subject & $\begin{array}{l}\text { No. of valid } \\
\text { cases }\end{array}$ & $\begin{array}{l}\text { Inter-rater agree- } \\
\text { ment (Kappa } \\
\text { values) }\end{array}$ \\
\hline Author to participant 1 & 4 & 0.914 \\
Author to participant 2 & 4 & 1.000 \\
Author to participant 3 & 4 & 0.915 \\
Author to participant 4 & 4 & 0.748 \\
Author to participant 5 & 4 & 0.831 \\
\hline
\end{tabular}

Kappa values and strength of agreements: $0.00-0.20$ : poor, $0.21-$ 0.40: fair, $0.41-0.60$ : moderate, $0.61-0.80$ : good, $0.81-1.00$ : very good

\subsubsection{Analysis method of the FFE studies}

The analysis method was referenced from other studies including Mendes and Oliveira (2015) which used a peerreview system and historical trend analysis along with a statistical approach.

1. Peer-review system: A peer-review system was employed to reinforce the internal validity of the analysis. A group of five NPD experts who had postgraduate qualifications and worked for more than 7 years in either a specific functional domain or a multitude of functional domains were selected. They conducted examinations on a preliminary selection of ten studies drawn evenly from the four different categories of the FFE study taxonomy, using the ten criteria. This included a comparison between the studies to identify corresponding items and assist the experts in unanimously agreeing on the validity of the analysis, an agreement that was only reached when an $80 \%$ match rate was attained. As presented in Table 1, through a statistical interpretation of the 'inter-rater agreement', kappa values were greater than 0.8 , meaning that each participant's level of agreement regarding the analyses was strong. Therefore, it was concluded that the remaining 256 studies could be analysed with the previously used method that was found to have high reliability.:After examining the 256 FFE studies, a batch of another ten papers were randomly chosen, and the five NPD experts confirmed the examination conducted on those ten papers, to review the internal validity of the analysis once again.

2. Historical trend analysis and statistical approach: The next analysis method was a two-pronged trend analysis: (1) a historical trend of particular characteristics and (2) their proportions (De Bellis 2009; Okubo 1997; Mendes and Oliveira 2015). Conway and Steward (2009) and Tidd et al. (2005) substantiated the merit of looking at the historical tendencies in the way innovation processes have evolved. Pahl et al. (2007) also listed various innovation processes, overviewing each in their study. In those two analyses, a statistical software package, SPSS Version 25.0, was used.:Studies on FFE issues and studies related to the FFE issue were also faithfully arranged alongside the FFE models, in chronological order. Since these FFE studies greatly affected the development of those FFE models, it was judged that including those studies in both charts would be of help in describing the FFE model development trends.

\section{Findings: FFE study features and development trends}

The ICL Research Data Repository (URL: http://doi.org/10. 14469/hpc/7725) shows a complete table analysed using the ten appraisal criteria and presents a list of 266 FFE studies. In the case of Figs. 3, 4, 5, 6, 7, 8, 9, 10, 11, 12, 13, 14, 15, 16,17 , the data in the ICL Repository have been converted into scatter plot graphs depicting historical development trends and tables (Tables 2, 3, 4, 5, 6, 7, 8, 9, 10, 11, 12, 13, $14,15,16)$ depicting their proportions, respectively.

\subsection{Appraisal standard dimension \#1: overall attributes of the FFE}

\subsubsection{Criterion \#1: study taxonomy}

There were relatively fewer independent FFE models focusing on FFE studies intensively, which comprised $27.4 \%$ of the data, than dependent FFE models extracted from wider product innovation processes, accounting for 52.3\% ( Table 2). It was in the 1990s, when the initial term for the early design stage, the FFE, emerged in a study by Reinertsen and Smith (1991), that FFE models and related studies began in earnest ( Fig. 3). Some of the representative models for intensive FFE study include M074 (Khurana and Rosenthal 1997), M095 (Koen et al. 2001) and M124 (Kim and Wilemon 2002a, b).

With the increasing importance of the FFE, studies looking at only one or two FFE tasks (though in great detail) were conducted, e.g., (1) opportunity discovery: M054 (Rochford, 1991), M123 (Rice et al. 2001); (2) ideation: M106 (Goldenberg et al. 1999), M153 (Li et al. 2006), M156 (Griffith and Grover 2006), M224 (Soukhoroukova et al. 2012), M229 (Reil et al. 2013), M239 (Gurtner et al. 2016); (3) product definition: M075 (Bacon et al. 1994), M104 (Bhattacharya et al. 1998), M175 (Agouridas et al. 2008) M221 (Jacoby 2012); and (4) conceptual design and 


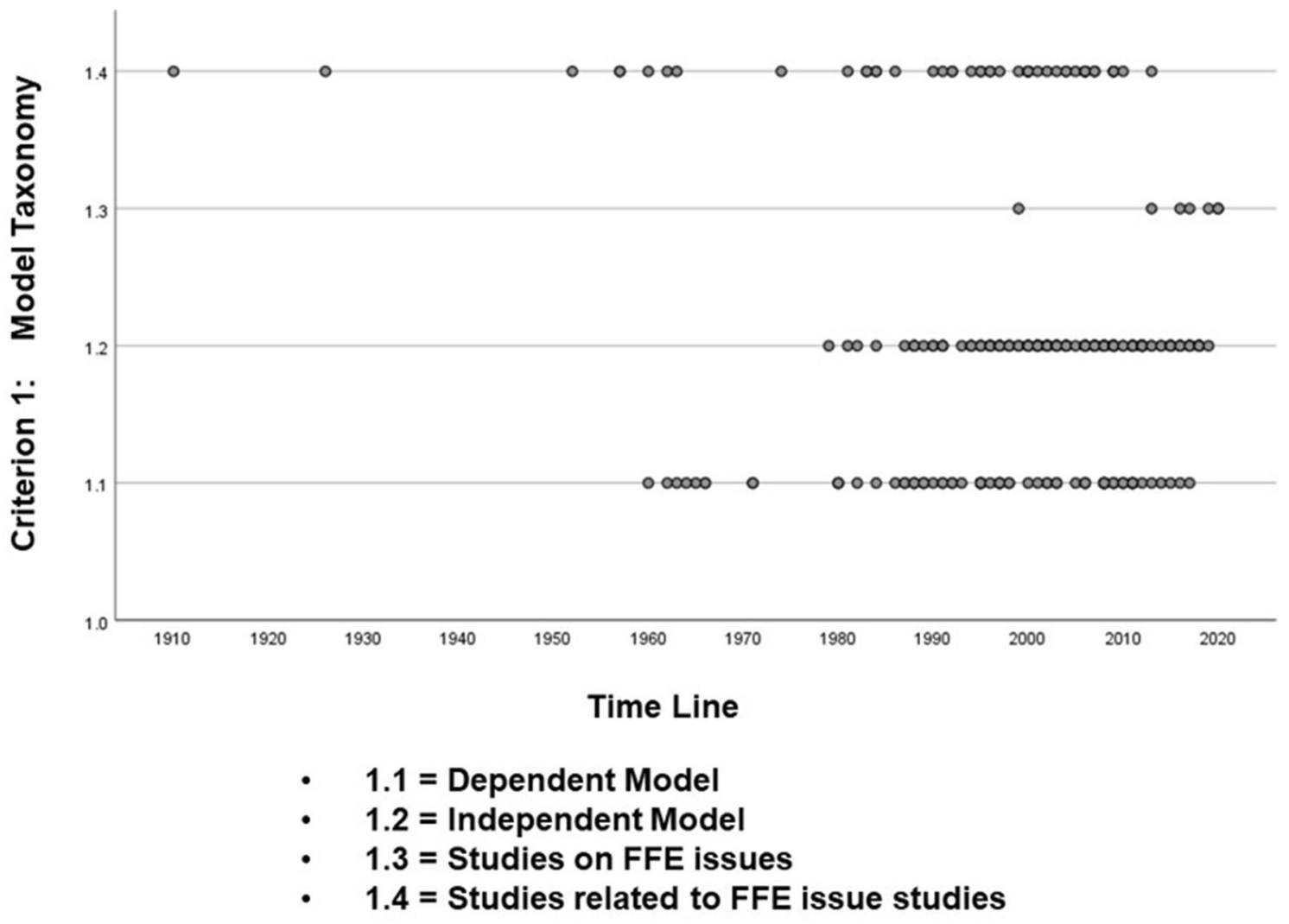

Fig. 3 Historical trend for criterion 1: model taxonomy

prototyping: M117 (AI Hakim et al. 2000), M119 (Genc et al. 2000), M164 (Seidel 2007), M186 (Zhang et al. 2009).

In addition, many studies were conducted to deal with issues generated in the FFE phase, e.g.: (1) fuzziness management: M126 (Zhang and Doll 2001), M134 (Kim and Wilemon 2002b, 2010), M168 (Chang et al., 2007); (2) decision-making: M71 (Shinno et al. 1994), M150 (Ziv Av and Reich 2005), M211 (Montagna 2011); (3) forecasting: M108 (Lynn et al. 1999), M161 (Lawrence et al. 2006), M162 (Meade and Islam 2006); (4) problem-solving: Shpakovsky (2006) examines diverse types of models and methods for solving problems; (5) knowledge creation and accumulation: Akbar et al. (2013) include a review of the literature regarding various types of knowledge generation and transmission models and methods.

Separately, NPD models whose initial stages can be regarded as the FFE have been developed and updated continually since the 1960s.

\subsubsection{Criterion \#2: model type}

The technology-push and market-pull type models, and their integrating or interactive variants, were found to be dominant, accounting for $44.4 \%$ of all models, compared to network-type models which accounted for only $20.7 \%$
( Table 3). Data-driven FFE models, which do not solely cover one or two FFE tasks but instead the entire range of the FFE, had not been devised yet (such models are far more recent): if the parameters are just produced but not processed in the structure of the model, the model can be regarded merely as a performative-type model.

As shown in Fig. 4, until the mid-1980s, most of the models of the technology-push type focused on developing elaborate machinery whose focus was on increasing the precision of technical processes and the quality of products, as well as reducing errors and risks (Bruce and Bessant 2002; Press and Cooper 2017). Towards the late 1980s, many experts recognised that engineering-centric models took too long and thus unable to keep up with the pace of the market (Cooper 1990, 2008; Griffin 1997). This led to a redesign of models to improve the hit rate of released product and reduce the development cycle time and the invested resources by applying marketing and management principles and methodologies (Cooper 1990, 2008; Griffin 1997). Namely, the model was rebuilt to include aspects from a marketing-pull type model, laid atop technology-push type models. Until the early 2000s, these integrating or interactive type models were continuously iterated to reinforce their merits and remove any limitations. 


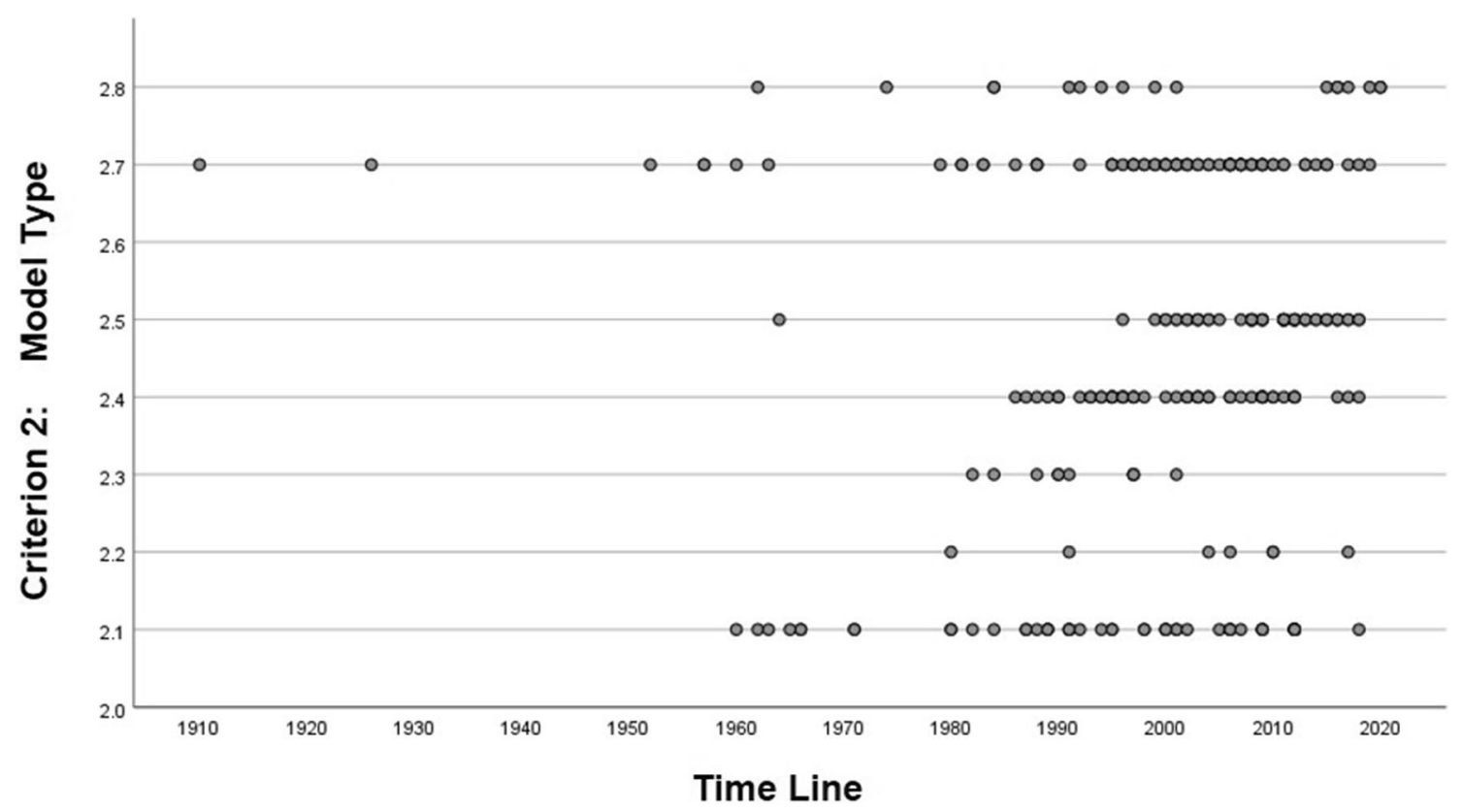

- $2.1=$ Technology-push

- $\quad 2.2$ = Market-pull

- $\quad 2.3=$ Coupling of 2.1 and 2.2

- $\quad 2.4$ = Interaction of 2.1 and 2.2

- $2.5=$ Network

- $2.6=$ Data-driven

- $2.7=$ Not Included $(\mathrm{N} / \mathrm{I})$

: The types above cannot be identified

- $\quad 2.8=$ Not Available (N/A)

: The study does not offer any model type

Fig. 4 Historical trend for criterion 2: model type

From the mid-2000s, following a trend of "Open Innovation", network-type models began to be devised which stressed communication between internal and external resources. An integration of two or three types of models to handle FFE issues was, notably revealed, such as: (1) integration of product and technology research with project portfolio management in M135 (Lawson and Finkelstein 2002); (2) integration of the business evaluation process and the technology cycle plan process in M165 (Backman et al. 2007); (3) integration of technology road-mapping and portfolio management in M199 (Oliveira and Rozenfeld 2010); (4) the integration of ideation process and project portfolio management in M223 (Heising 2012); (5) interaction between design and technology research in M232 (Goto et al. 2014).

With the emergence of "Industry 4.0" where conception, embodiment, and application of NPD are operated by datadriven systems, data-driven model types are in high demand. Model types that have evolved from network-based models are required not only for optimum collection and analysis of NPD-related information but also the efficient conversion of that information into usable knowledge format which can be applied to NPD projects in the future.

\subsubsection{Criterion \#3: NPD speed}

There were comparatively few studies on agile development, which comprised only $9.0 \%$ of the total ( Table 4). The concept of agile NPD was produced in the early 2000s, and its reflection in models has actively continued to this day ( Fig. 5). In most these models, tasks and activities are overlapped or carried out in parallel to realise rapid development. The main purpose of this main mechanism is to reduce the wait time for other tasks and activities to be completed. The representative model for this approach is shown in studies by Cooper (2014) and Cooper and Sommer (2018) in whose models the structure has evolved from the initial model, 


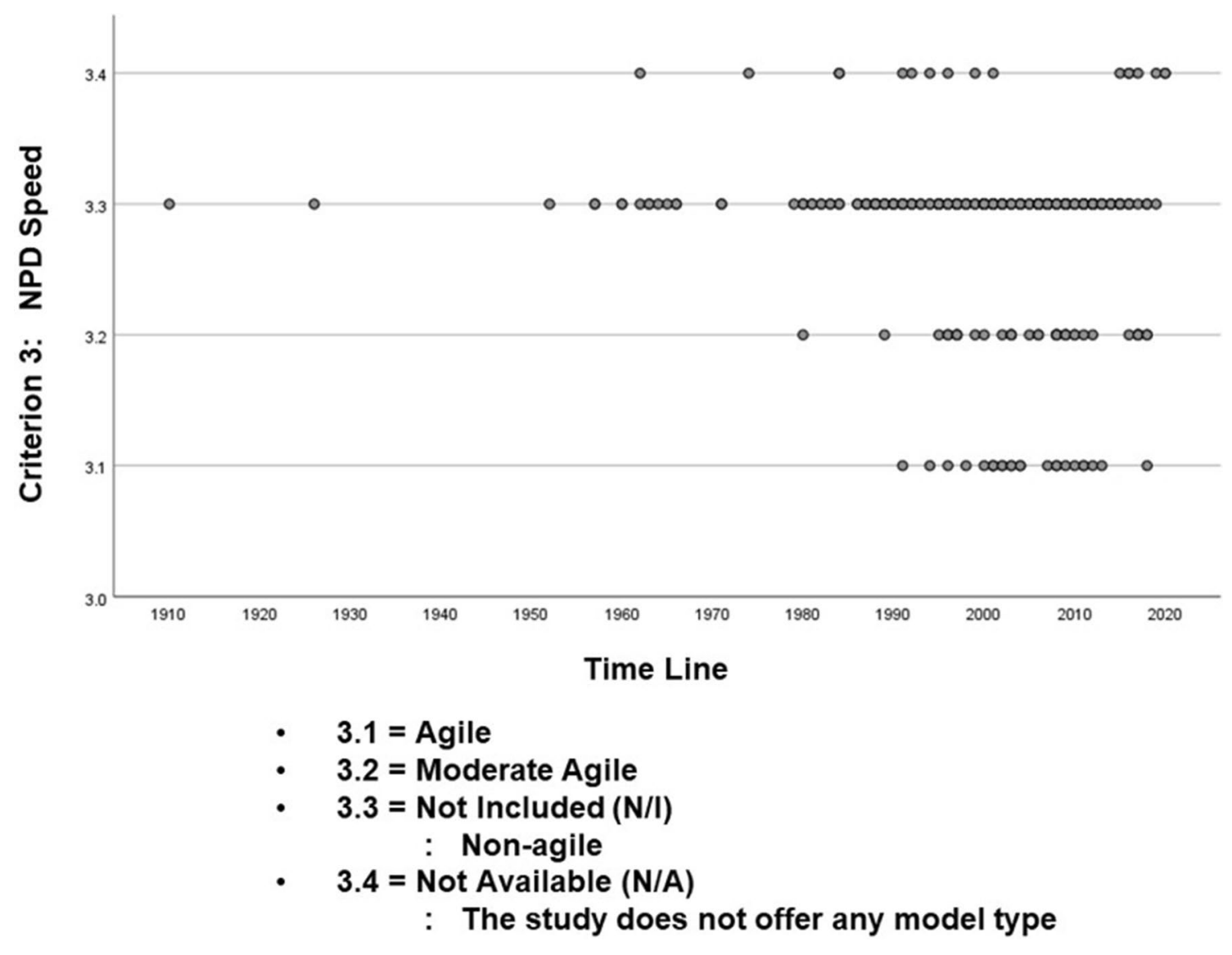

Fig. 5 Historical trend for criterion 3: NPD speed

M036 (Cooper 1983), addressing the fast-repetition cycle in the pursuit of agility.

However, before the concept of agile NPD was produced, there were models which had pursued rapid development with iterative and overlapped NPD cycle, e.g., M055 (Clark and Fujimoto 1991), M074 (Reinertsen 1994), and M102 (Thomke et al. 1998). Besides, the concurrent engineering mode and another similar agile NPD method were revealed in M034 (Andreasen and Hein 1987), M073 (O'Connor 1995), and M087 (Prasad 1996, 2000; Prasad et al. 1998).

\subsubsection{Criterion \#4: NPD attribute}

There are a comparatively large number of models for solely incremental NPDs, and also many models inclined more towards incremental rather than radical development even if not solely incremental in nature. The proportion of models for radical NPDs was comparatively low at a total rate of just 4.9\% ( Table 5).

As shown in Fig. 6, around the mid-1980s where the "New-to-the-Company" (NTC) type, as well as the "Additions-to-the-Existing-Product-Line" (AEL) type (Carbone and Tippett 2014), was required in markets, radical NPD appeared to gain traction in the research community. A generation of new technologies and the inflow of user needs to new markets provoked both the academy and industry into researching radical NPDs, e.g., M114 (Sheremata 2000), M123 (Rice et al. 2001), M164 (Seidel 2007), and M233 and M234 (Verganti 2008; 2011). Studies targeting both types, including M130 (Nobelius and Trygg 2002) and M178 (Verworn et al. 2008), have been produced since the early 2000s.

\subsubsection{Criterion \#5: model characteristic}

For models whose form is robustly fixed, "Explicitness" predominates in the analysis with a rate of $50.4 \%$ ( Table 6). Most of the models in this type belong to the linear phasebased model type, which have been dominant in industry (Castilho et al. 2015; Kurkkio 2011) as well as being the subject of study in academia (Cooper and Edgett 2008; Simms 2012). The most recent models for this phasedtype were M141 (Fairlie-Clarke and Muller 2003), M159 (Osteras et al. 2006), M205 (Luchs and Swan 2011), and M036 (Cooper 2018).

To solve problems associated with the linear type, e.g., lack of suitability for performing radical NPDs and 


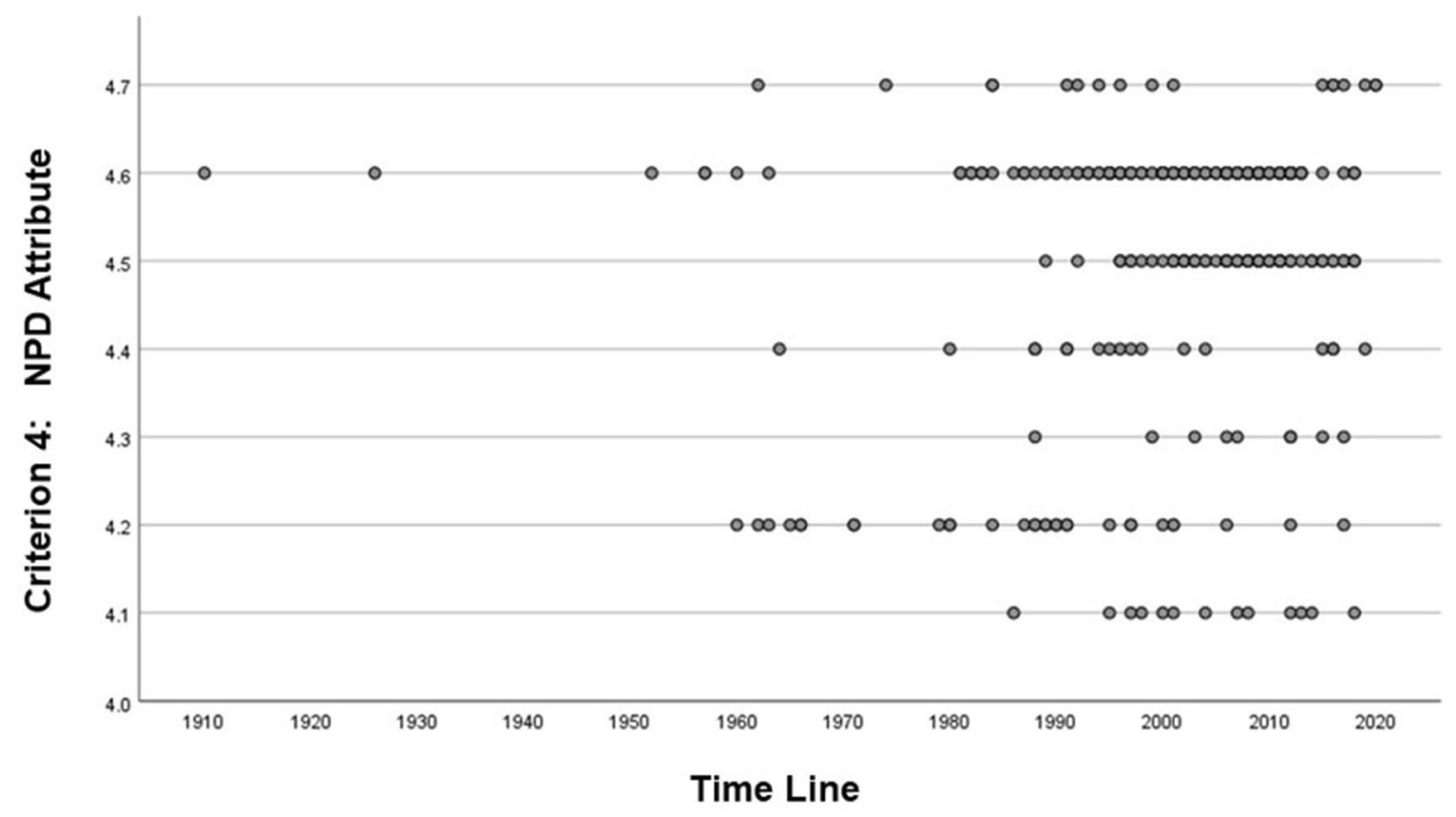

- $\quad 4.1=$ Radical NPDs

- $\quad 4.2=$ Incremental NPDs

- $\quad 4.3=$ Radical NPDs > Incremental NPDs

- 4.4 = Radical NPDs < Incremental NPDs

- $\quad 4.5=$ Both Radical NPDs and Incremental NPDs

- $4.6=$ Not Included (N/I)

: The attributes above cannot be identified

- $\quad 4.7=$ Not Available (N/A)

: The study does not offer any model type

Fig. 6 Historical trend for criterion 4: NPD attribute

generating creative outcomes, a more flexible model structure, a nonlinear type; "Responsiveness", e.g., a recursive, chaotic, spiral, and complex adaptive system framework type (Buijs 2003; Sperry and Jetter 2009), started to be developed (McCarthy et al. 2006; Simms 2012) from around the late 1990s (Fig. 7). Examples of this type, whose structure pursues the nonlinear type, can be found in, for example, M137 (Hüsig and Kohn 2003), M144 (Phaal et al. 2004), and M194 (Cascini et al. 2009).

Since the mid-2000s, structures of models have evolved to combine and intertwine the various types previously mentioned, while the simple, pure, linear phase-structured type of process has been abandoned (Dershin 2010; Tidd et al. 2005). The optimal form of this model is viewed to be a balance between "Explicitness" for more rational reasoning and to generate scientific outcomes under stable control and "Responsiveness" to allow unconstrained processes to generate creative results under flexible management. The first type is a circular, funnel, or spiral sub-structure (termed a "Recursive" structure) rooted in the main phased frame, e.g., M173 (Michael 2008), M174 (El-Sayed 2008), M175 (Agouridas et al. 2008), and M177 (Barczak et al. 2009). Conversely, there is the type which forms a sequential sub-structure based on the recursive frame, e.g., M143 (Trott 2008), M185 (Kutvonen and Torkkeli 2009), and M197 (Slack 2010). The last type is not the integration of the linear and nonlinear structures but a modular, phased structure in which the form can change flexibly. Representative cases were found in M130 (Nobelius and Trygg 2002), M165 (Backman et al. 2007), and M241 (Salerno 2015) in which modes of the model can be transformed depending upon the type of project. Based on these models which embody various types in the pursuit of both "Explicitness" and "Responsiveness", basic principles on how to balance the two-mode directions can be accomplished along with related knowledge and theories. 


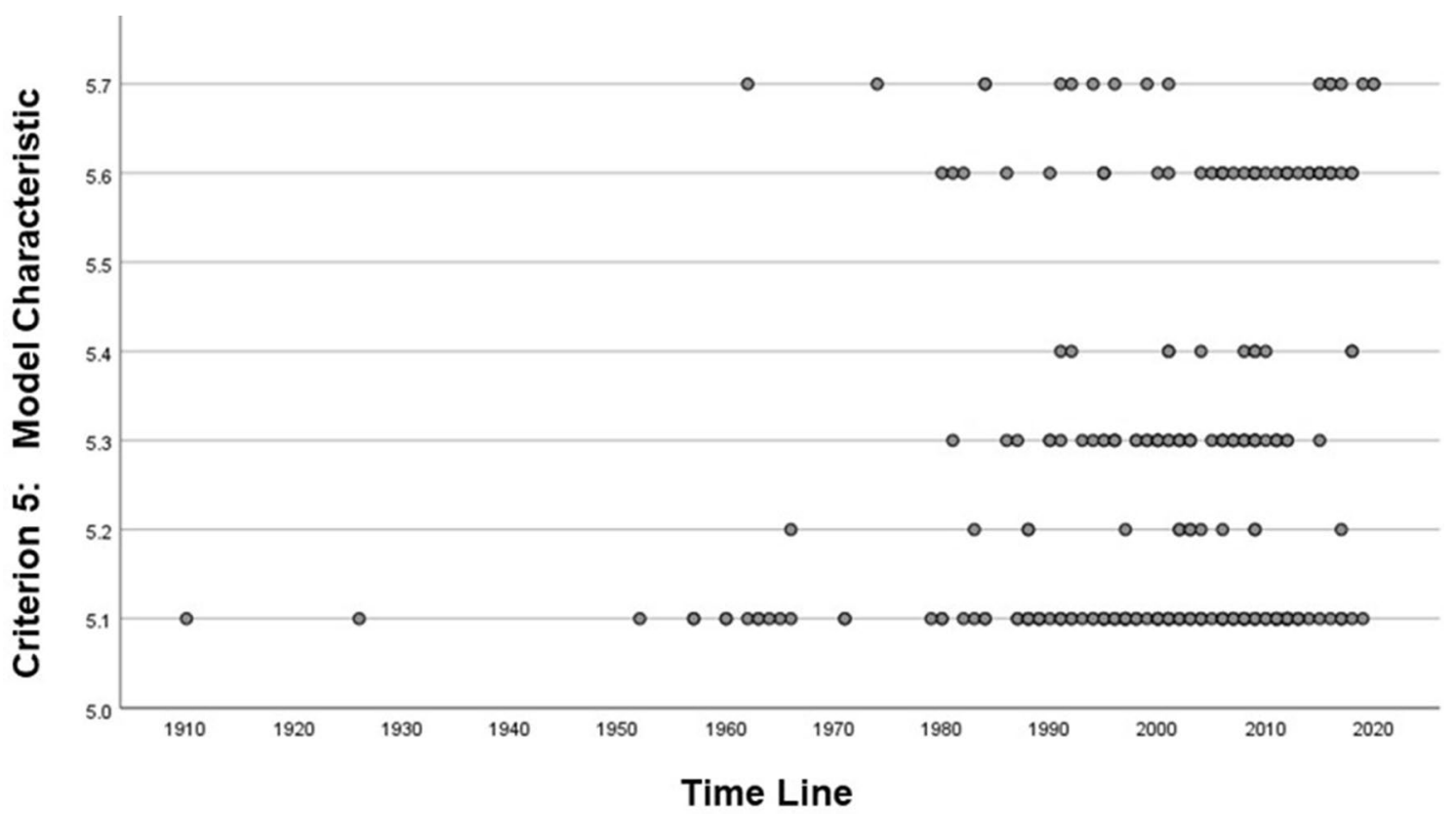

- $\quad 5.1=$ Explicitness

- $\quad 5.2=$ Responsiveness

- $\quad 5.3=$ Explicitness $>$ Responsiveness

- $\quad 5.4=$ Explicitness < Responsiveness

- $\quad 5.5=$ Both Explicitness and Responsiveness

- $5.6=$ Not Included (N/I)

: The characteristics above cannot be identified

- $\quad 5.7=$ Not Available (N/A)

: The study does not offer any model type

Fig. 7 Historical trend for criterion 5: model characteristic

\subsubsection{Criterion \#6: model structure}

Almost all of the models were of the procedure type models. Compared against the number of performative-type models, the ratio was 10:1 ( Table 7). The procedure type concentrates on the structural anatomy of the model and its components, considering 'what' tasks and activities should be carried out. On the other hand, the performative type, also known as the toolkit type, focuses on functional compositions and the operating mechanism in accordance with certain formalities, considering 'how' tasks and activities can be done. As shown in Fig. 8, so far, for the performance type models studied, none cover the entire range of the FFE phase. The current performative models, accounting for 5.3\% ( Table 7), focused on one or two FFE tasks only. M059 (Cavallucci 2001) and M106 (Goldenberg et al. 1999) are example models for the idea generation task. Performative models for the product specifications (and conceptual design) task include M073 (O'Connor
1995), M127 (McKay et al. 2001), and M150 (Ziv Av and Reich 2005). For product function and system structure in the product architecture aspect, M046 (Ito et al. 1989) and M071 (Shinno et al. 1994) are representative cases.

Also, a model which effectively balances the performative and procedural styles has yet to be identified. A mixed type which comes close, wherein the performative aspects are actualised based on a procedural style (or vice versa) accounts for only $5.3 \%$ (1.9\%) of the models examined. M033, conducted by Hubka and Eder $(1987,1996)$, is the most typical case for this mixed type. This model has a phased structure with each phase consisting of an input and output system which serves as a toolkit platform called a "Technical System" (TS). In the case of models M087 (Prasad 1996) and M088 (Prasad, 2000), the version developed in 1996, M087, is much more related to the toolkit type, while its successor, M088, evolved from the 1996 version and has a procedural structure based on the performative style. 


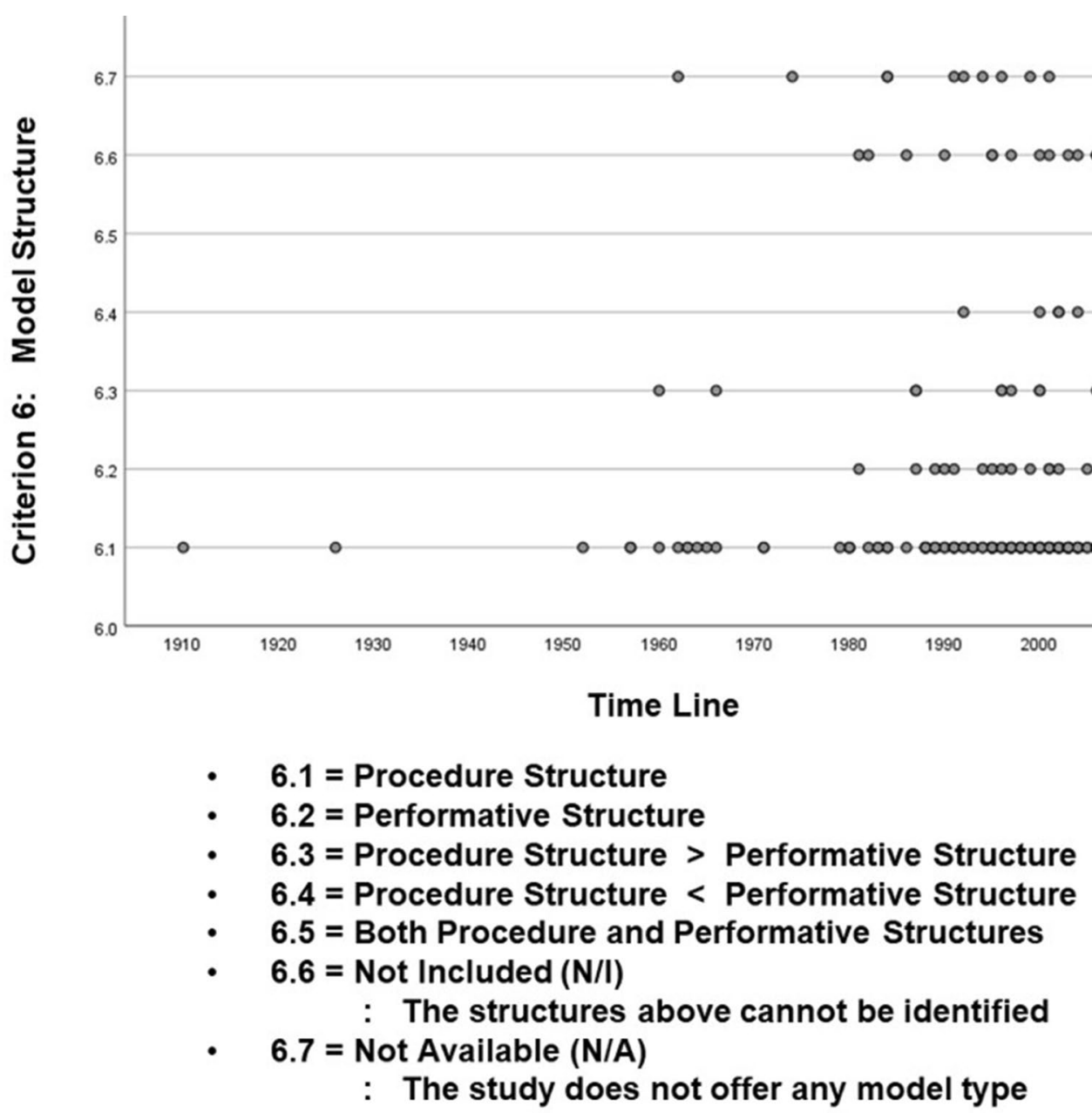

Fig. 8 Historical trend for criterion 6: model structure

\subsection{Appraisal standard dimension \#2: FFE performance structure}

\subsubsection{Criterion \#7: FFE task}

Hüsig and Kohn (2003) and Carbone and Tippett (2014) contend that definitions and descriptions of FFE tasks vary from expert to expert. Moreover, the border between FFE tasks is becoming progressively obscure with more tasks now being associated with each other (Alam 2006a, b; Yoon and Jetter 2015). Therefore, it is difficult to explicitly define what FFE tasks should be inclusive or exclusive when developing a new FFE model. However, FFE tasks can be divided into several categories based on their similar roles and functions, and it should be noted that there are a number of variant terms for these tasks. In the study by Dewulf (2013), many different terms for tasks defined by various scholars have been categorised into a smaller number of groups on the basis of the roles and functions; similar tasks are grouped together.
Except for models which cater particularly and exclusively to one or two FFE tasks, most of the models investigated here were identical in that they catered to the same number and type of task. A total of 28 different terms were initially enumerated from the 266 FFE studies. These gathered tasks were sorted again into six groups. These six taxonomic groups are also observed in many studies in the literature, such as Khurana and Rosenthal (1998), Koen et al. (2002), Kim and Wilemon (2002a, b), Nobelius and Trygg (2002), and Thomke and Fujimoto (2000).

Figures 9, 10 and Tables 8, 9 indicate that opportunity identification (Task 1) and idea generation (Task 2) are core tasks, with around $66 \%$ of all models stressing on these two tasks. Many authors, including De Brentani and Reid (2012), Gurtner and Reinhardt (2016), and Wormald (2011), argue that FFE models should be built based on those two tasks as the vital components of the FFE, since most NPD-related information which can be directly applied to the actual NPD phase later is produced here. 


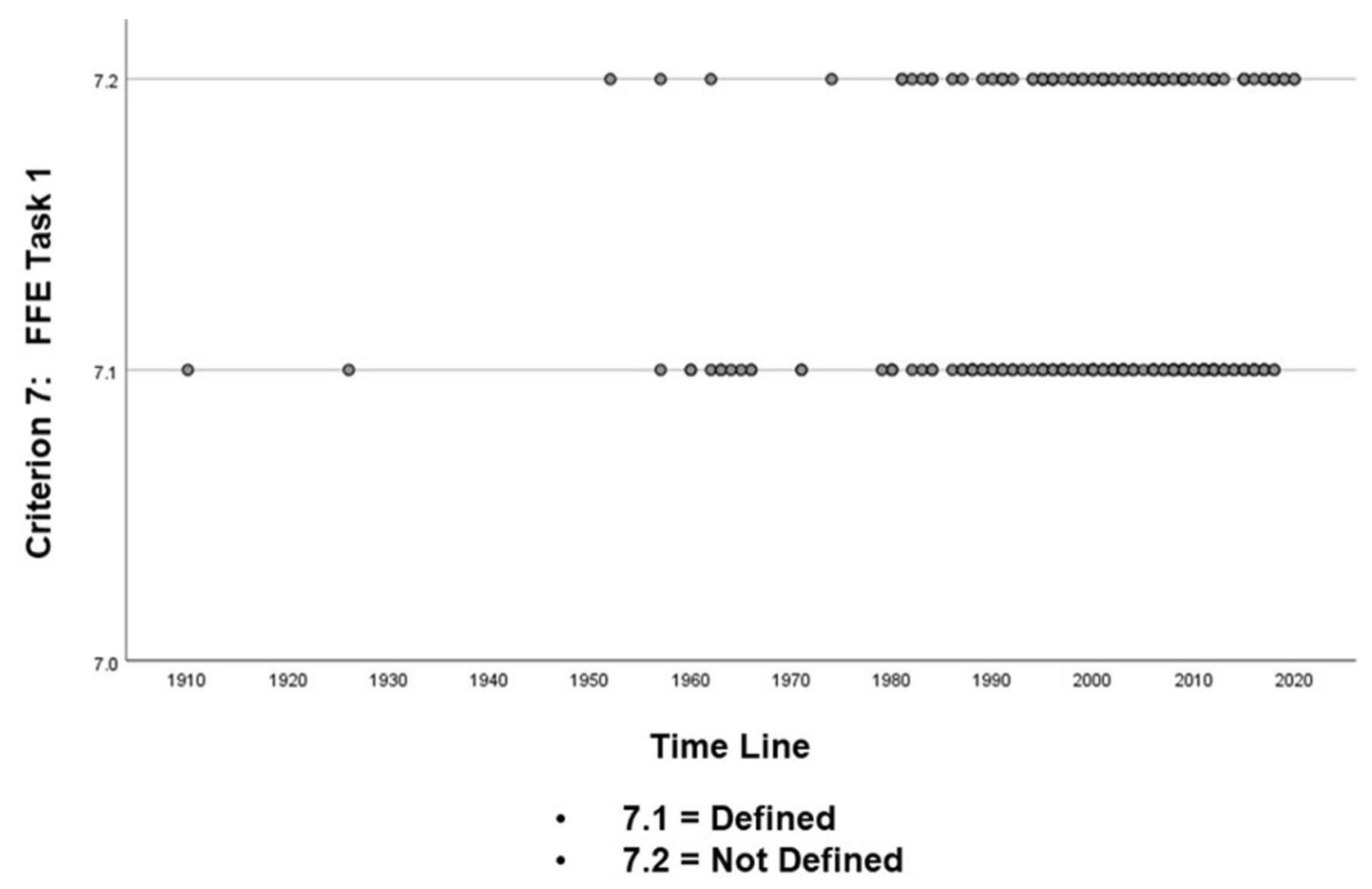

Fig. 9 Historical trend for criterion 7: Task 1 -opportunity identification

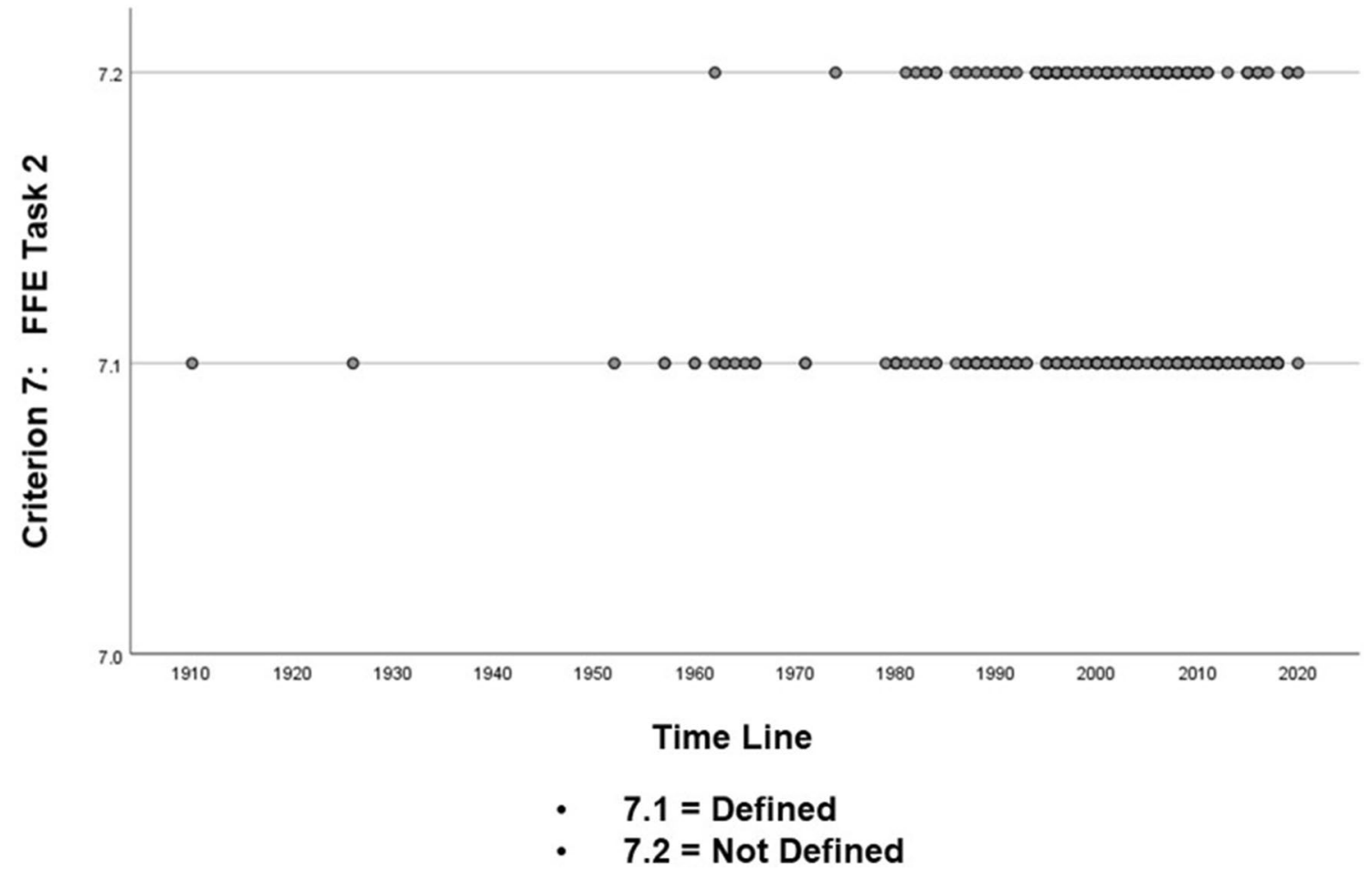

Fig. 10 Historical trend for criterion 7: Task 2-idea generation 


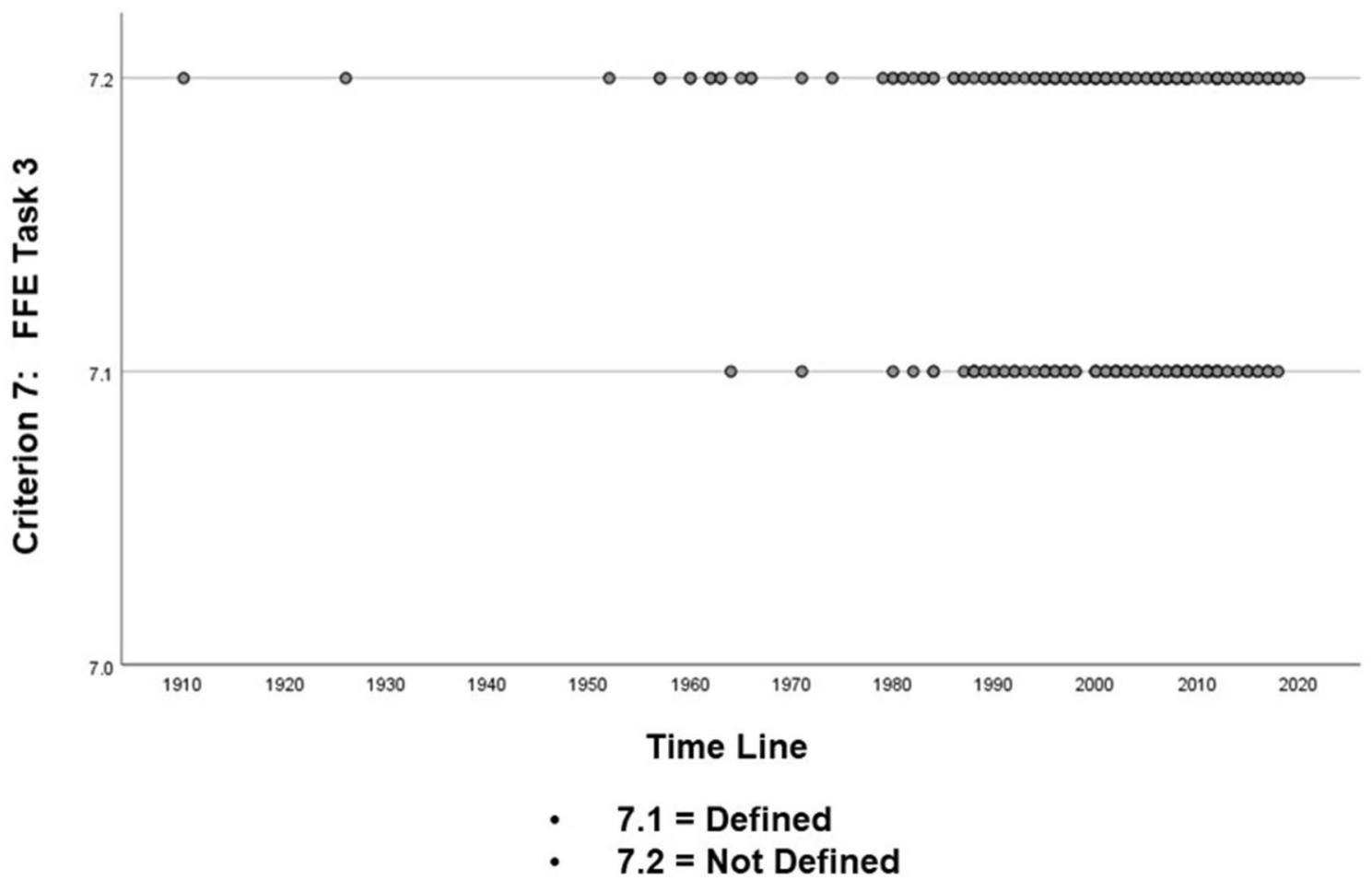

Fig. 11 Historical trend for criterion 7: Task 3-mission statement

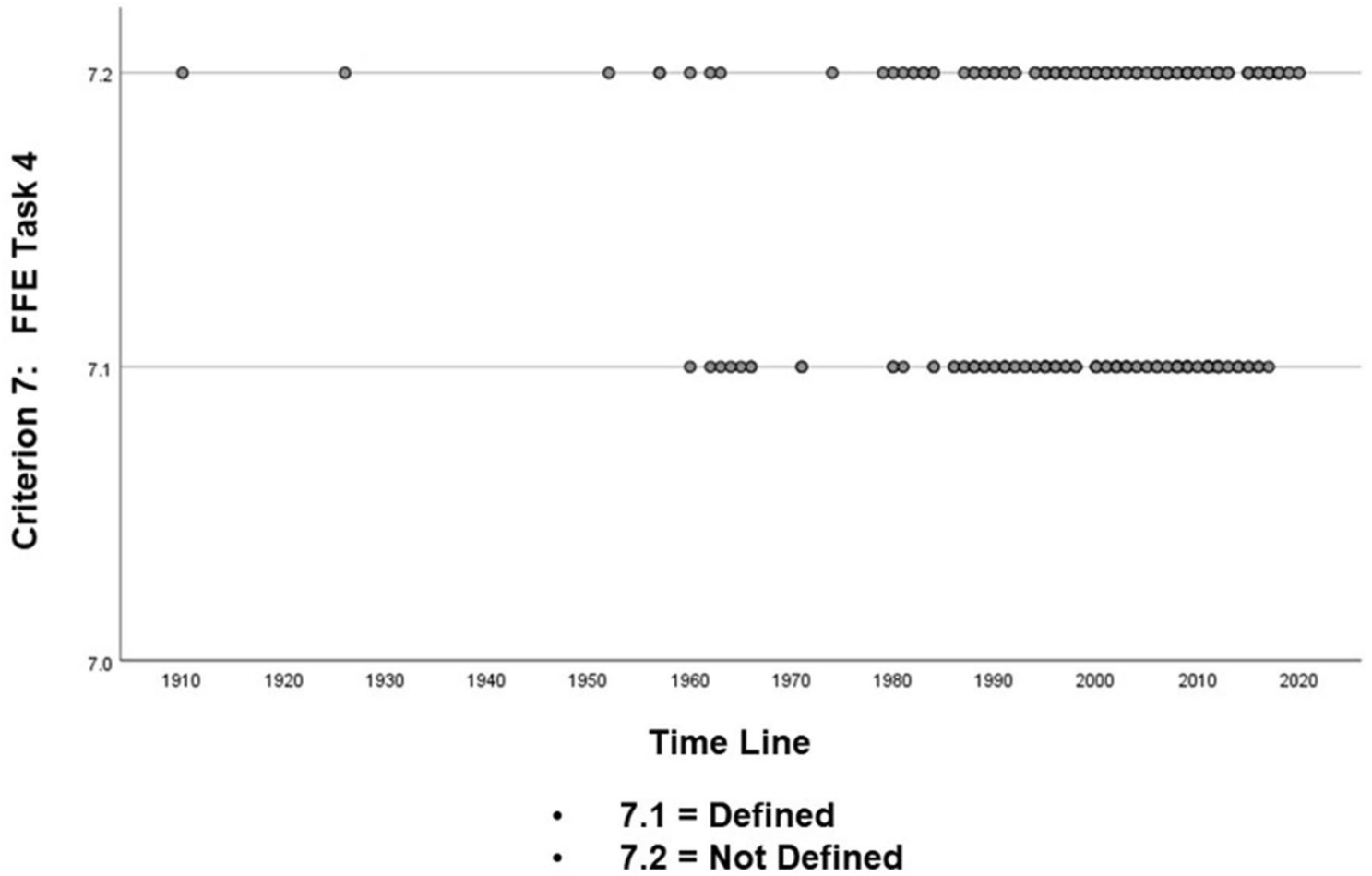

Fig. 12 Historical trend for criterion 7: Task 4-requirements list 


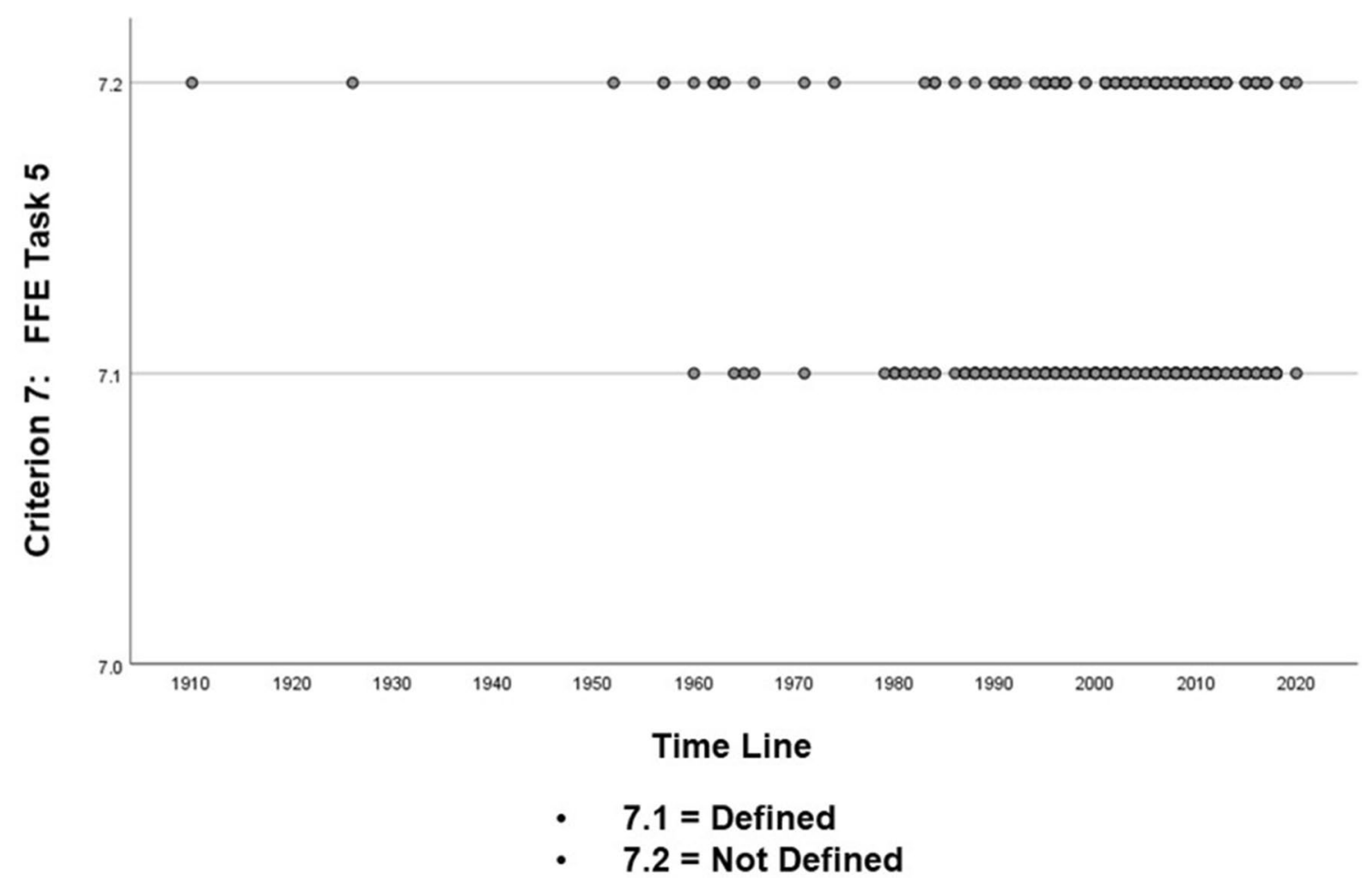

Fig. 13 Historical trend for criterion 7: Task 5-conceptual design

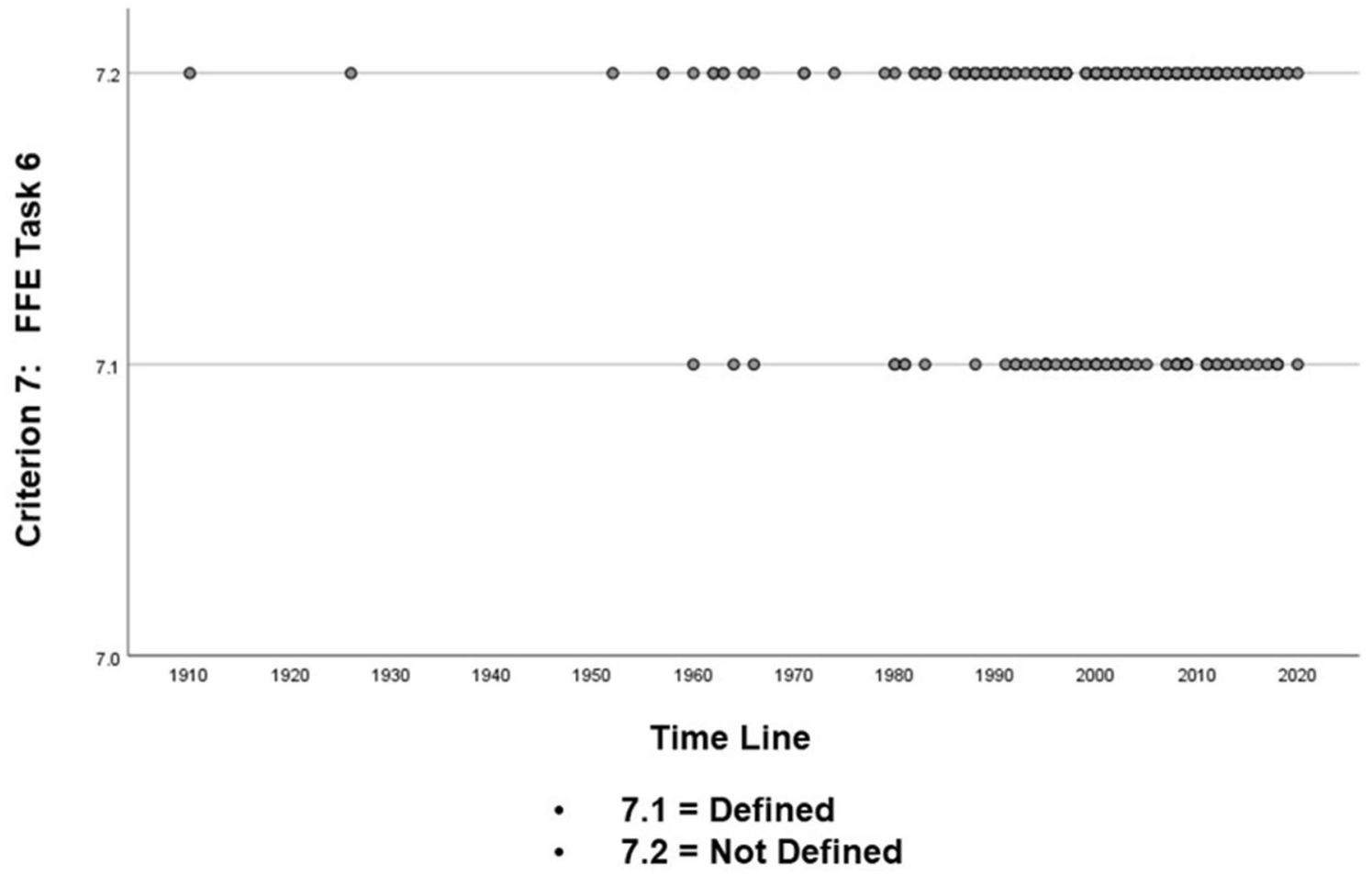

Fig. 14 Historical trend for criterion 7: Task 6-prototyping 


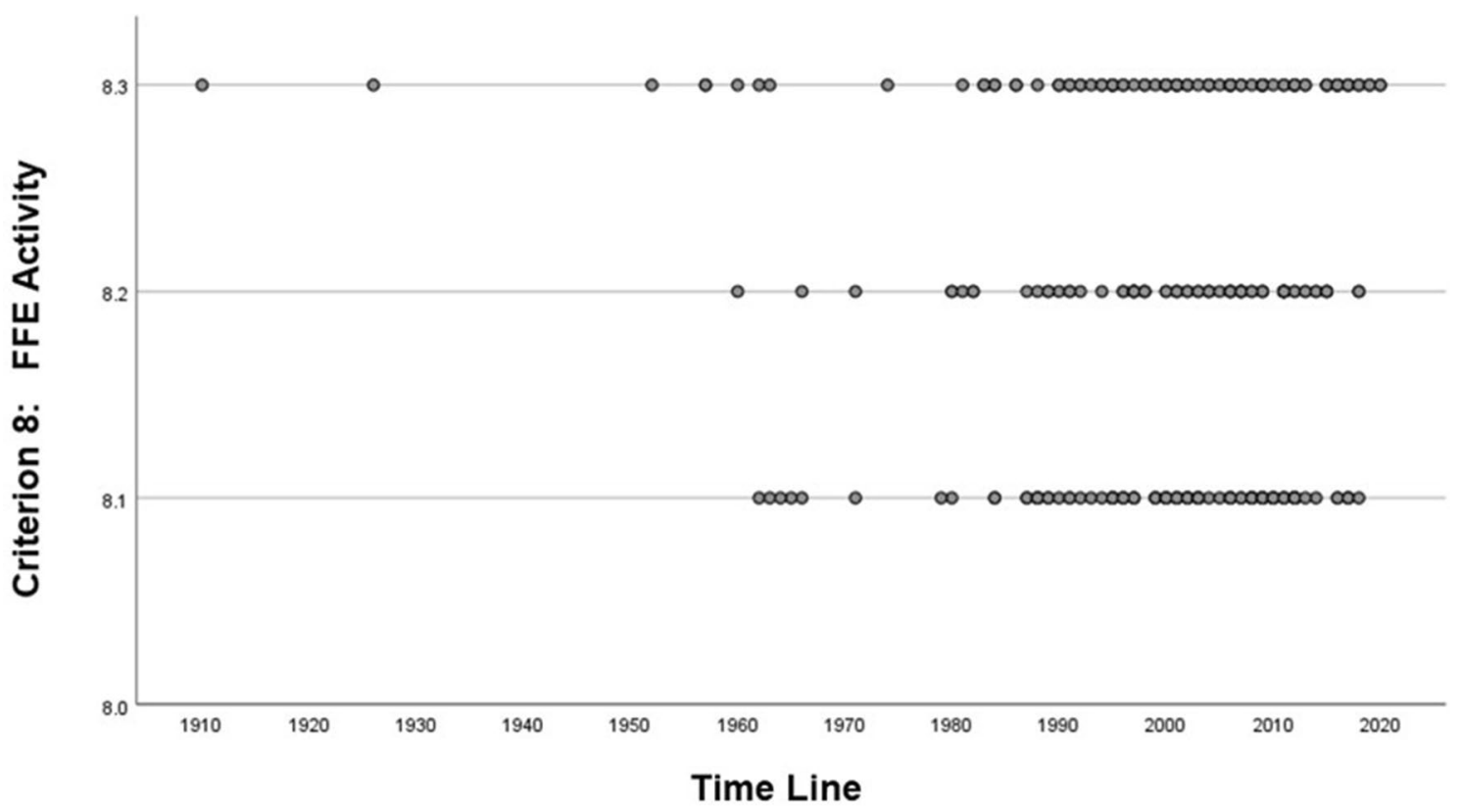

- $\quad 8.1=\mathrm{N} \geq 3$

- $8.2=\mathrm{N} \leq 2$

- $8.3=N=0$

( $N=$ The Number of FFE Activities)

Fig. 15 Historical trend for criterion 8: FFE activity

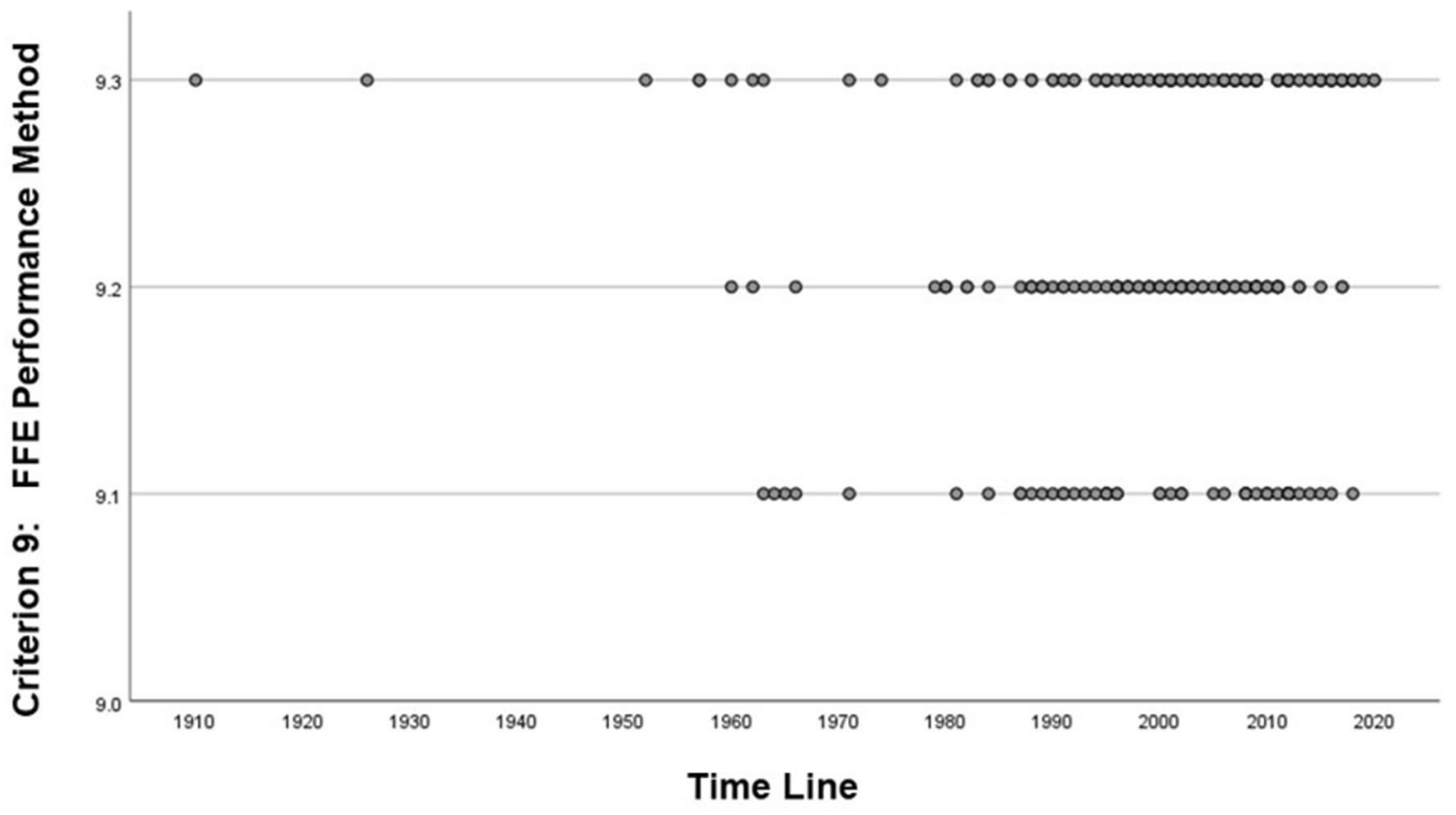

- $\quad 9.1=$ Specific Description

- $\quad 9.2=$ Brief Description

- $9.3=$ Non-description

Fig. 16 Historical trend for criterion 9: FFE performance method 


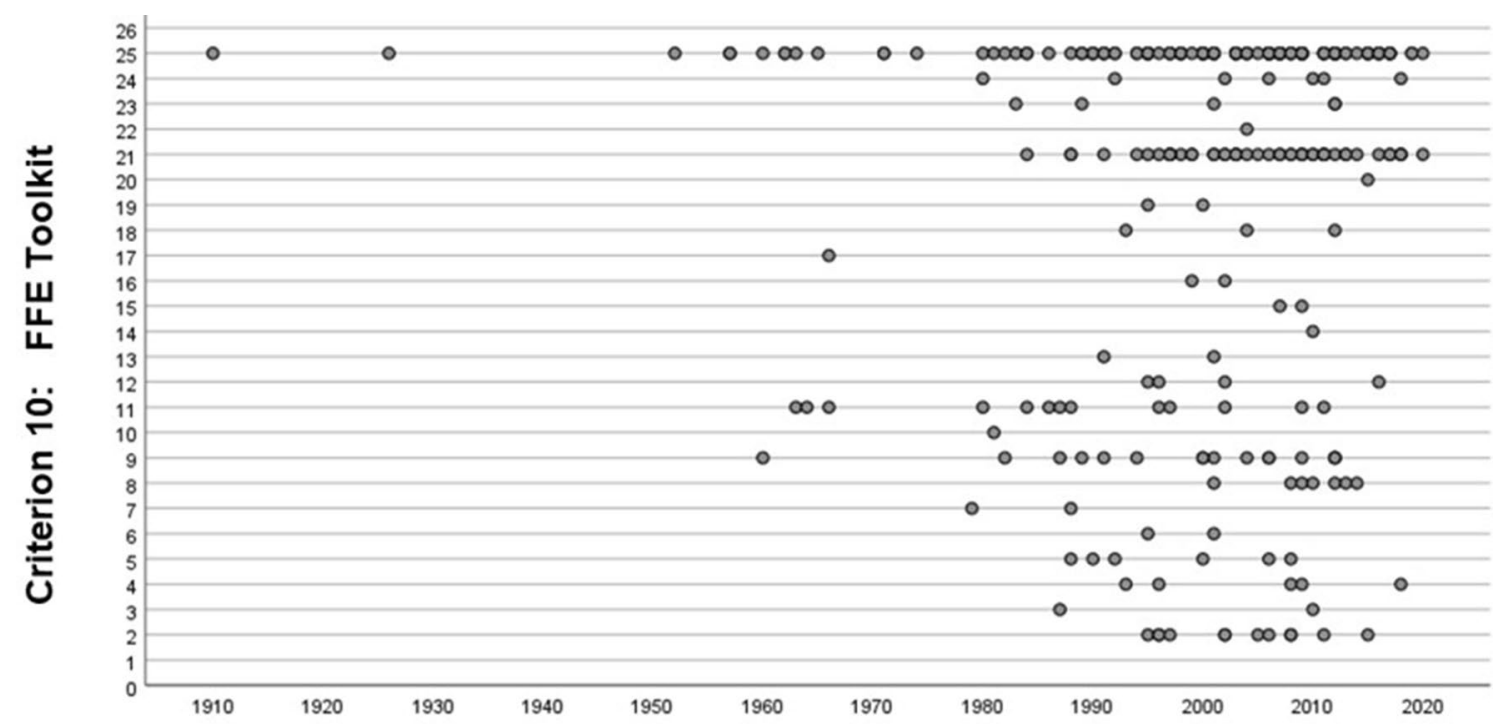

Time Line

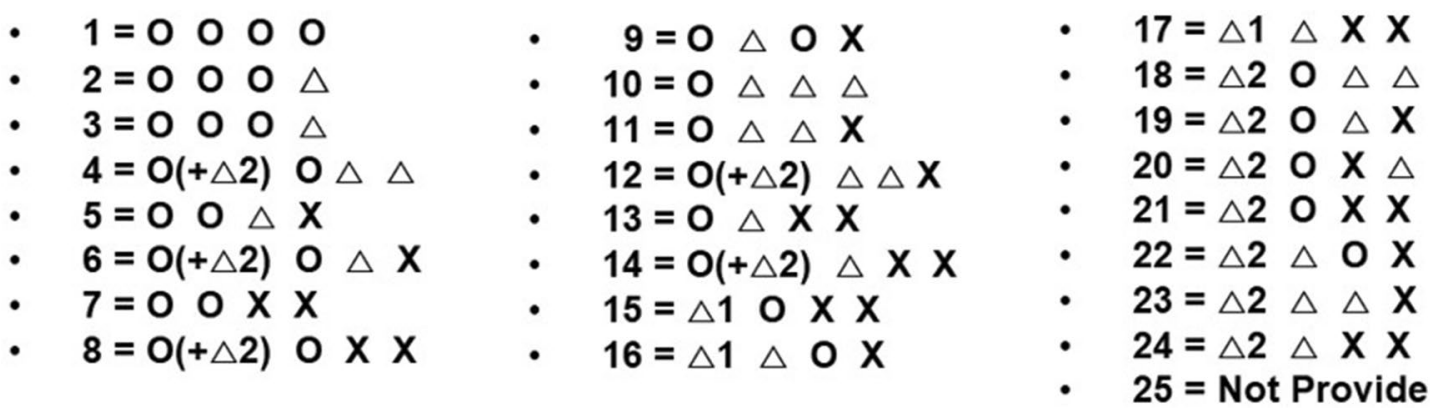

The meaning of each code above can be found in the Imperial College London Data Repository

Fig. 17 Historical trend for criterion 10: FFE toolkit

Table 2 Frequency analysis for criterion 1: model taxonomy

\begin{tabular}{llrcc}
\hline Valid & Frequency & Percent & Valid (\%) & Cumulative (\%) \\
\hline 1.1 & 73 & 27.4 & 27.4 & 27.4 \\
1.2 & 139 & 52.3 & 52.3 & 79.7 \\
1.3 & 7 & 2.6 & 2.6 & 82.3 \\
1.4 & 47 & 17.7 & 17.7 & 100.0 \\
Total & 266 & 100.0 & 100.0 & \\
\hline
\end{tabular}

The importance of the mission statement (Task 3) and requirements list (Task 4) has also been emphasised at the initial design stage for a very long period ( Figs. 11, 12, and Tables 10,11), since the main purpose of the FFE is to define a design brief and product specifications, such that they become the input parameters for the beginning of the actual NPD (Carbone and Tippett 2004; Jacoby and Scheelen 2012; Williams et al. 2007).
Table 3 Frequency analysis for criterion 2: model type

\begin{tabular}{lllll}
\hline Valid & Frequency & Percent & Valid (\%) & Cumulative (\%) \\
\hline 2.1 & 49 & 18.4 & 18.4 & 18.4 \\
2.2 & 7 & 2.6 & 2.6 & 21.1 \\
2.3 & 10 & 3.8 & 3.8 & 24.8 \\
2.4 & 52 & 19.5 & 19.5 & 44.4 \\
2.5 & 55 & 20.7 & 20.7 & 65.0 \\
2.6 & 0 & 0 & 0 & 65.0 \\
2.7 & 76 & 28.6 & 28.6 & 93.6 \\
2.8 & 17 & 6.4 & 6.4 & 100.0 \\
Total & 266 & 100.0 & 100.0 & \\
\hline
\end{tabular}

The most controversial issue among the six FFE tasks is whether the conceptual design and prototyping tasks should be included. In the case of the conceptual design task, in the 1970s, it med to be included in the embodiment design or 
Table 4 Frequency analysis for criterion 3: NPD speed

\begin{tabular}{llrcc}
\hline Valid & Frequency & Percent & Valid $(\%)$ & Cumulative (\%) \\
\hline 3.1 & 24 & 9.0 & 9.0 & 9.0 \\
3.2 & 35 & 13.2 & 13.2 & 22.2 \\
3.3 & 190 & 71.4 & 71.4 & 93.6 \\
3.4 & 17 & 6.4 & 6.4 & 100.0 \\
Total & 266 & 100.0 & 100.0 & \\
\hline
\end{tabular}

Table 5 Frequency analysis for criterion 4: NPD attribute

\begin{tabular}{llrcc}
\hline Valid & Frequency & Percent & Valid $(\%)$ & Cumulative (\%) \\
\hline 4.1 & 13 & 4.9 & 4.9 & 4.9 \\
4.2 & 30 & 11.3 & 11.3 & 16.2 \\
4.3 & 9 & 3.4 & 3.4 & 19.5 \\
4.4 & 17 & 6.4 & 6.4 & 25.9 \\
4.5 & 56 & 21.1 & 21.1 & 47.0 \\
4.6 & 124 & 46.6 & 46.6 & 93.6 \\
4.7 & 17 & 6.4 & 6.4 & 100.0 \\
Total & 266 & 100.0 & 100.0 & \\
\hline
\end{tabular}

Table 6 Frequency analysis for criterion 5: model characteristic

\begin{tabular}{lllll}
\hline Valid & Frequency & Percent & Valid (\%) & Cumulative (\%) \\
\hline 5.1 & 134 & 50.4 & 50.4 & 50.4 \\
5.2 & 14 & 5.3 & 5.3 & 55.6 \\
5.3 & 51 & 19.2 & 19.2 & 74.8 \\
5.4 & 11 & 4.1 & 4.1 & 78.9 \\
5.5 & 0 & 0 & 0 & 0 \\
5.6 & 39 & 14.7 & 14.7 & 93.6 \\
5.7 & 17 & 6.4 & 6.4 & 100.0 \\
Total & 266 & 100.0 & 100.0 & \\
\hline
\end{tabular}

Table 7 Frequency analysis for criterion 6: model structure

\begin{tabular}{lllll}
\hline Valid & Frequency & Percent & Valid $(\%)$ & Cumulative (\%) \\
\hline 6.1 & 175 & 65.8 & 65.8 & 65.8 \\
6.2 & 14 & 5.3 & 5.3 & 71.1 \\
6.3 & 14 & 5.3 & 5.3 & 76.3 \\
6.4 & 5 & 1.9 & 1.9 & 78.2 \\
6.5 & 0 & 0 & 0 & 78.2 \\
6.6 & 41 & 15.4 & 15.4 & 93.6 \\
6.7 & 17 & 6.4 & 6.4 & 100.0 \\
Total & 266 & 100.0 & 100.0 & \\
\hline
\end{tabular}

detail-design stage. As shown in Fig. 13 and Table 12, the conceptual design task (Task 5) in the 1970s was included in the embodiment design phase. However, since the 1980s, the conceptual design and embodiment design tasks have
Table 8 Frequency analysis for criterion 7: Task 1-opportunity identification

\begin{tabular}{llccc}
\hline Valid & Frequency & Percent & Valid $(\%)$ & Cumulative (\%) \\
\hline 7.1 & 172 & 65.7 & 65.7 & 64.7 \\
7.2 & 94 & 35.3 & 35.3 & 100.0 \\
Total & 266 & 100.0 & 100.0 & \\
\hline
\end{tabular}

Table 9 Frequency analysis for criterion 7: Task 2-idea generation

\begin{tabular}{llrcc}
\hline Valid & Frequency & Percent & Valid $(\%)$ & Cumulative (\%) \\
\hline 7.1 & 179 & 67.3 & 67.3 & 67.3 \\
7.2 & 87 & 32.7 & 32.7 & 100.0 \\
Total & 266 & 100.0 & 100.0 & \\
\hline
\end{tabular}

Table 10 Frequency analysis for criterion 7: Task 3-mission statement

\begin{tabular}{llccc}
\hline Valid & Frequency & Percent & Valid $(\%)$ & Cumulative (\%) \\
\hline 7.1 & 116 & 43.6 & 43.6 & 43.6 \\
7.2 & 150 & 56.4 & 56.4 & 100.0 \\
Total & 266 & 100.0 & 100.0 & \\
\hline
\end{tabular}

Table 11 Frequency analysis for criterion 7: Task 4-requirements list

\begin{tabular}{llrcc}
\hline Valid & Frequency & Percent & Valid (\%) & Cumulative (\%) \\
\hline 7.1 & 132 & 49.6 & 49.6 & 49.6 \\
7.2 & 134 & 50.4 & 50.4 & 100.0 \\
Total & 266 & 100.0 & 100.0 & \\
\hline
\end{tabular}

Table 12 Frequency analysis for criterion 7: Task 5-conceptual design

\begin{tabular}{llccc}
\hline Valid & Frequency & Percent & Valid $(\%)$ & Cumulative (\%) \\
\hline 7.1 & 172 & 64.7 & 64.7 & 64.7 \\
7.2 & 94 & 35.3 & 35.3 & 100.0 \\
Total & 266 & 100.0 & 100.0 & \\
\hline
\end{tabular}

Table 13 Frequency analysis for criterion 7: Task 6-prototyping

\begin{tabular}{llccc}
\hline Valid & Frequency & Percent & Valid $(\%)$ & Cumulative (\%) \\
\hline 1 & 70 & 26.3 & 26.3 & 26.3 \\
2 & 196 & 73.7 & 73.7 & 100.0 \\
Total & 266 & 100.0 & 100.0 & \\
\hline
\end{tabular}


Table 14 Frequency analysis for criterion 8: FFE activity

\begin{tabular}{llccc}
\hline Valid & Frequency & Percent & Valid (\%) & Cumulative (\%) \\
\hline 8.1 & 104 & 39.1 & 39.1 & 39.1 \\
8.2 & 71 & 26.7 & 26.7 & 65.8 \\
8.3 & 91 & 34.3 & 34.3 & 100.0 \\
Total & 266 & 100.0 & 100.0 & \\
\hline
\end{tabular}

Table 15 Frequency analysis for criterion 9: FFE performance method

\begin{tabular}{llccc}
\hline Valid & Frequency & Percent & Valid $(\%)$ & Cumulative (\%) \\
\hline 9.1 & 54 & 20.3 & 20.3 & 20.3 \\
9.2 & 85 & 32.0 & 32.0 & 52.3 \\
9.3 & 127 & 47.7 & 47.7 & 100.0 \\
Total & 266 & 100.0 & 100.0 & \\
\hline
\end{tabular}

Table 16 Frequency analysis for criterion 10: FFE toolkit

\begin{tabular}{|c|c|c|c|c|}
\hline Valid & Frequency & Percent & Valid (\%) & Cumulative (\%) \\
\hline 1 & 0 & 0 & 0 & 0 \\
\hline 2 & 12 & 4.5 & 4.5 & 4.5 \\
\hline 3 & 2 & 0.8 & 0.8 & 5.3 \\
\hline 4 & 5 & 1.9 & 1.9 & 7.1 \\
\hline 5 & 6 & 2.3 & 2.3 & 9.4 \\
\hline 6 & 2 & 0.8 & 0.8 & 10.2 \\
\hline 7 & 2 & 0.8 & 0.8 & 10.9 \\
\hline 8 & 7 & 2.6 & 2.6 & 13.4 \\
\hline 9 & 16 & 6.0 & 6.0 & 19.4 \\
\hline 10 & 1 & 0.4 & 0.4 & 19.9 \\
\hline 11 & 13 & 4.9 & 4.9 & 24.8 \\
\hline 12 & 4 & 1.5 & 1.5 & 26.3 \\
\hline 11 & 2 & 0.8 & 0.8 & 27.1 \\
\hline 14 & 1 & 0.4 & 0.4 & 27.4 \\
\hline 15 & 2 & 0.8 & 0.8 & 28.2 \\
\hline 16 & 2 & 0.8 & 0.8 & 28.9 \\
\hline 17 & 1 & 0.4 & 0.4 & 29.3 \\
\hline 18 & 3 & 1.1 & 1.1 & 30.5 \\
\hline 19 & 2 & 0.8 & 0.8 & 31.2 \\
\hline 20 & 1 & 0.4 & 0.4 & 31.6 \\
\hline 21 & 48 & 18.0 & 18.0 & 49.6 \\
\hline 22 & 1 & 0.4 & 0.4 & 50.0 \\
\hline 23 & 5 & 1.9 & 1.9 & 51.9 \\
\hline 24 & 7 & 2.6 & 2.6 & 54.4 \\
\hline 25 & 121 & 45.5 & 45.5 & 100.0 \\
\hline Total & 266 & 100.0 & 100.0 & \\
\hline
\end{tabular}

been more clearly separated, with an increase in the significance of the conceptual design task (Backman et al. 2007). Conceptual design is crucial in reducing iterative work (such as tinkering with design specifications) in the actual NPD phase (Hüsig and Kohn 2003; Zhang et al. 2009). In the case of the manufacturing prototypes, since the 1990s, with the trend of "Manufacturable Design" (Verganti 2011), also called "Design for Manufacturability" (Barczak et al. 2009), most of the FFE models come with a prototyping task (Task 6 ) in addition to the conceptual design task. From that point on ( Fig. 14, Table 13), many studies dealing solely with conceptual design and prototyping have also been produced, e.g., M109 (Ozer 1999), M121 (Dahan and Mendelson 2001), and M213 (Kim and Kim 2011). At the time of writing, the prototyping task and the conceptual design task have become essential parts of the FFE. Christiansen and Gasparin (2017) and Ester and Daniel (2007) have insisted that the prototyping task should be incorporated into the FFE stage, since modifications to designs can arise from prototype testing. "Google Design Sprint" and "IBM Design Thinking" are models which also stress on the roles and functions of those two tasks. However, it can be noted that prototyping is relevant to many activities across design and limiting it to one stage is not necessarily appropriate.

Along with those trends, whether the conceptual design and prototyping tasks were included in the FFE or the embodiment- or detail-design stage seems to have also depended on organisations' inherent NPD execution styles, application capability and maturity, scale of funding, etc. Indeed, this issue still remains controversial. However, as stated in research by Bacciotti et al. (2016), Borgianni et al. (2018), Ester and Daniel (2007), and Roach (2020), and as shown in Fig. 13, the trend is clear; these tasks are being incorporated into the FFE.

\subsubsection{Criterion \#8: FFE activity}

As shown in Fig. 15 and Table 14, models which list more than two FFE activities for each task account for $39.1 \%$ of all models examined in this study. Models which address one or two activities per task account for $26.7 \%$. The majority of these models are of the prescriptive type, whereas specific FFE activities are not defined explicitly in the descriptive type due to its intrinsic nature.

\subsubsection{Criterion \#9: FFE performance method}

The outcomes here are similar to, and can be examined in the same context as, the outcomes of the previous criterion. As shown in Fig. 16, Table 15, the more theoretical and conceptual models account for $47.7 \%$ of the models; they contain a lower level of detail when describing performance methods of FFE activities. On the other hand, more pragmatic and prescriptive models particularly tended to illustrate performance methods and techniques step by step. 


\subsubsection{Criterion \#10: FFE toolkit}

Many toolkit types in which NPD-related input and output parameters are evident, including a chart, matrix, flowchart, break-down structure, root-cause analysis type, or their combined version with particular functional and morphological characteristics, have been developed so far, for wider and general NPD. Also, there have been studies devoted to toolkits for the FFE stage, e.g., Achiche et al. (2013) and Ester and Daniel (2007). However, most FFE studies on toolkits were not dealing with new toolkit developments targeting the initial design stage, considering performance structure and its operating mechanisms of toolkits. Those studies tended to just figure out what performance methods and associated toolkits were reasonable for each FFE task and how frequently these toolkits are typically provided to each FFE task.

In this paper, the type, performance structure, and operating mechanism of the toolkits provided in the current 266 FFE studies were explored. In the case of FFE components that extended into the actual NPD process, the analysis was limited to the toolkits used within the FFE phase. The first and third sub-criteria, 'Concreteness' and 'Contextuality', are associated with 'Contextual Performance', while the second and fourth sub-criteria, 'Functionality' and 'Cooperability', relate to 'Concurrent Collaboration'. Here, contextual performance which can generally be activated in a single functional domain is defined as a performance structure where output parameters from previous toolkits flow into subsequent toolkits as input parameters. Hence, each parameter from other parameters in the contextual performance relationship of a single functional domain can be inferred. Second, concurrent collaboration which can commonly be fostered in multidimensional domains is defined as performance structure where each of the toolkits involved in cross-functional work are structurally and functionally connected with each other. This leads to enabling inferring each parameter from other parameters in the concurrent collaboration relationship across multiple functional domains.

As shown in Fig. 17, Table 16, where the development trend and the portion of characteristics of toolkit sets (decided by the four sub-criteria) are depicted, a total of 24 distinct patterns were observed.

As noted in the study of these 24 patterns ( Table 16), none were identified to contain toolkit sets which could entirely fulfil with all four sub-criteria. For those that aimed at one or two FFE tasks and covered a single functional domain, the toolkit set has strength in terms of contextual performance, although limitations could be identified in the domain of concurrent collaboration. Indeed, these limitations can also be found in toolkit sets that aim at all elements of the front-end from the viewpoint of a single functional domain. On the other hand, toolkit sets that encompass the entire range of FFE tasks from the perspective of multiple functional domains typically lack an interrelationship with each other in regard to contextual performance and concurrent collaboration. The reason is that the toolkit sets heavily reference representative toolkits which have already been provided from various prior studies with little consideration of their linkage. Limitations and challenges in both contextual performance and concurrent collaboration will increase relying upon the increasing number of FFE tasks and functional domains that these toolkit sets aim to cover.

In terms of toolkit development trend ( Fig. 17), model structures with self-developed toolkits received a great deal of attention in the 1960s and 1970s. It would appear that the development of these toolkits commenced in earnest alongside the development of prescriptive FFE models. From then until the late 1990s, attention on studies about model structures, operation methods, and the correlation between relevant issues were much more stressed, producing both the descriptive and prescriptive model types. Those studies had also tendency to recommend referencing toolkits previously developed; there were very few cases of models devising their own toolkits. With the cross-functional work trend on the rise, there was a tendency to propose many toolkit sets developed in multiple functional fields for use in new models. From the early 2000s, when the potential to represent particular differences in structures and operating systems of models was initiating to decline, efforts to determine how to perform tasks and activities more efficiently med to resume. A movement towards offering more specific toolkits reached a peak in the late 2000s. Around this time, many studies on concrete toolkits and their guidelines were carried out, which resulted in various educational materials for a massive set of toolkits, e.g., Human-Centred Design Toolkit (IDEO, 2003, 2009), Universal Design Toolkit 1 and 2 (Lidwell et al. 2010; Hanington and Martin 2012), 101 Design Toolkit (Kumar 2012), Cambridge's Inclusive Design Toolkit (Clarkson et al. 2007, 2013), and TU Delft's Design Guide (van Boeijen et al. 2014).

\subsection{A summary of FFE study analysis}

The outcomes of the analysis of the 266 FFE studies using ten criteria have been conducted. Many cues for the establishment of strategies for the development of a new FFE model have been identified. However, there are some few aspects that should not be neglected when looking at those analysis along with cues.

In the analysis tables and figures, the fact that a high percentage of studies handle a particular aspect does not indicate that studies on that aspect are no longer demanded. On the other hand, it cannot be asserted that studies carried out on a certain aspect should be intensified in the future just, since the proportion of studies dedicated 
Table 17 Evidential cues for FFE model development strategies

\begin{tabular}{|c|c|}
\hline $\begin{array}{l}\text { Appraisal } \\
\text { criterion }\end{array}$ & Analysed evidential cues (Based on the analysis in Sect. 3, 'Findings: FFE study features and development trends') \\
\hline 1 & Few models only for the FFE have been developed \\
\hline 2 & $\begin{array}{l}\text { No data-driven models covering the entire range of the FFE have been developed although the trend of data-driven performance } \\
\text { becomes increasing }\end{array}$ \\
\hline 3 & Few models for agile development have been developed although the trend of agile performance is recently accelerated \\
\hline 4 & Few models for both incremental and radical NPD have been developed \\
\hline 5 & Few models whose characteristic is balanced between "Explicitness" and "Responsiveness" have been developed \\
\hline 6 & $\begin{array}{l}\text { Few models with structure harmonised between the procedure and performative types (particularly, a procedural structure with } \\
\text { performative-type sub-structures) have been developed }\end{array}$ \\
\hline 7 & $\begin{array}{l}\text { There are the following six tasks in the FFE: (1) Opportunity Identification, (2) Idea Generation, (3) Mission Statement, (4) } \\
\text { Requirements List, (5) Conceptual Design, and (6) Prototyping }\end{array}$ \\
\hline 8 & Few models providing essential FFE activities which involves diverse functional domains have been developed \\
\hline 9 & Few models offering each performance method of diverse activities have been developed \\
\hline 10 & $\begin{array}{l}\text { None of the toolkits provided by FFE models have been developed in consideration of both contextual performance and concurrent } \\
\text { collaboration }\end{array}$ \\
\hline
\end{tabular}

to that aspect is low. To establish a strategy for developing a new FFE model, development trends thus far, the necessities of the modern age, and forecasting of the future circumstances could be considered. For example, though the agile development model development has been comparatively fervent over the past twenty years with a steep growth trend, which does not imply that its significance is now beginning to taper off. It stands to reason that studies on the development of models to accelerate the NPD cycle will be still demanded, to develop different structures and more innovative operating mechanisms in agile systems.

Next, not all of the studies fall neatly into the time periods in the trend graph. The interpretation must be that the chart depicts a comprehensive trend, not trapping into scrutinising each model and the time division in detail. However, the overall analysis of FFE studies as a function of time allows not only boosting the understanding of comprehensive trends but offering a blueprint for a new FEE model development.

Finally, it does not represent that there is nothing to be attained from models and their relevant studies, even if some aspects are not functionally or structurally well established in those models. Even in this case, useful resources for a new model development can be obtained.

\section{Discussion: a new FFE model development strategies (drivers)}

This section addresses the establishment of new FFE model development strategies based on the key analysis by each evaluation criterion. A summary of evidential cues for the development strategies can be found in Table 17.

\subsection{Strategy dimension \#1: overall attributes of the FFE}

\subsubsection{Strategy \#1: a demand of intensive FFE model development}

In many cases, numerous research centres and corporations continue to be under the misapprehension that the back-end component of product innovation process, including the embodiment design, detailed design, and design optimisation phases, have the greatest impact on final NPD outputs (Kurkkio 2011; Williams et al. 2007; Yoon et al. 2015). This has given rise to developing and improving back-end models rather than the front-end models. Even though there has been much progress in studies on the FFE in the meantime, it seems to be necessary to devise and advance the FFE component intensively in more specific and a diverse range of aspects including the perspectives of criteria established in this study.

\subsubsection{Strategy \#2: a data-driven type with an information processing and knowledge accumulation}

With the demands of modern business, e.g., 'Innovation 4.0 'and pressures for remote operation, FFE models have been forced towards the data-driven type. The data-driven type concentrates not on representing a structure in which NPD-related parameters merely produced in the model itself, which can be regarded as the performative structure, but on indicating a structure wherein those parameters are processed in the model itself. Therefore, the embodiment of the data-driven type is not just associated with the performative structure (Strategy \#5), but is closely related to that of the performative structure consisting of a series of 
toolkits interlocking each other for contextual performance and concurrent collaboration (Strategy \#10).

\section{Information processing}

The data-driven type of FFE model demands a platform which operates on the basis of "Information Processing" (Carbone and Tippett 2014; Poskela and Martinsuo 2009). Information processing (O'Connor and Rice 2001; Dröge et al. 2008; Leenders et al. 2003) does not simply mean the collection of information but also a systematic and structured process for producing actionable findings based on both "Factual" and "Value" principles (Reid and De Brentani 2004; Koen et al. 2002). The core point is this structured system, to convert "Factual" data into usable "Value" which can be applied to the NPD (Reid and De Brentani 2004). Collection has a tendency to be informal, and so, a formalised system of collection is vital (Dewulf 2013; Jacoby 2012). Mere collection and analysis are less longer sufficient; a systematic process for transforming data into actionable information is required.

Information processing has two aspects: (1) "Speed of Information Flow" (Kim and Wilemon 2002a, b) and (2) "Quality of Information Flow" (Millson et al. 1992). In the case of speed of information processing, which is of help to affecting first-mover merits and supporting a business achieve an edge over the competition (Kerin et al. 1992; Langerak and Hultink 2005), there are "Three Moderators" (Boulding and Christen 2003). These moderators are rapid customer response, rapid market positioning, and rapid intellectual protections. Concerning the quality of information processing, which is beneficial for more superior NPDs realised by generating more accurate information and by reducing uncertainty and ambiguity, there are two models. Laswell's (1948) model, a typical information processing system, has a phased structure comprised of "Information Source", "Encoding", "Transmission Channel", "Receiver", "Decoding", "Noise", and "Feedback". Rogers' model (2010) complemented Laswell's by adopting diffusion theory to improve Laswell's three components: "Receiver", "Decoding", and "Noise". A control system for both "Receiver Variables" and "Social System Variables" was incorporated into the process from "Receiver" via "Decoding" to "Noise".

2. Knowledge accumulation

Implementing a system of information processing, even if in pursuit of 'speed' and 'quality', is less sufficient to make a model a data-oriented model. There is a demand for an equal focus on converting the processed information into usable knowledge assets. This is sometimes known as the transition from "Perception" to "Cognition" (De Brentani and Reid 2012; Roos 1996).
"Perception" means to recognise, gather, and analyse certain patterns in a given set of information, while "Cognition" means the ability to reconstruct that information and transform it into applicable formats for the organisation and its tasks. The data gained from "Cognition" are viewed as a knowledge asset, evolved from information processing by "Perception".

There are numerous studies on knowledge accumulation. Akbar and Tzokas (2013) and Du Chatenier et al. (2009) reviewed diverse knowledge accumulation theories. According to their studies, knowledge accumulation is a loop process which enables processed data to be utilised sustainably (Armbrecht et al. 2001; Talke et al. 2006). The loop system operates as a cycle: (1) track past information, (2) discover current information, (3) envisage future-oriented information through a combination and transformation of past and current information, (4) conduct a feasibility study of new information, (5) build up knowledge, and 6) go back to step one (Goodman and Lawless 1994; Usher 2013). Through iteration of the cycle, the system of accumulating knowledge is learned, with know-how and expertise on relevant sectors acquired by each NPD project (Armbrecht et al. 2001; Kim and Wilemon 2002a, b; Talke et al. 2006).

3 . The integration of information processing and knowledge accumulation

By putting the information processing and knowledge accumulation systems together, an ideal data-led type of the model, serving as a knowledge-based platform, can be embodied. It plays a role in managing relevant gathered information through reinforced information processing capabilities for depth and breadth, after which the accumulated knowledge can be disseminated to proper projects in the future. In particular, for the initial design phase, a model devised specifically for processing qualitative rather than quantitative data is highly demanded, as much of what is acquired during the front end is non-countable (Dewulf 2013; Lukas and Menon 2004; Wowak et al. 2016). Since the FFE phase involves a considerable degree of uncertainty and ambiguity (Brun and Saetre 2009; Kurkkio 2011) and thus highly possible to obtain subjective and approximate information (Kim and Wilemon 2002a, b), it is likely that there is much information that cannot be quantified.

In summary, the data-driven FFE model can be embodied by strengthening the information processing and knowledge accumulation capacity of a model which concentrates more on qualitative information. 


\subsubsection{Strategy \#3: agile development by increasing the quality of information flow}

To realise a new, agile type of FFE model, a new method needs to be created, instead of most of the previous models' method which has achieved agility by conducting a rapid iteration system or by enabling parallel, overlapping implementations. This system wherein constant loop-backs and their iterations tend to be regarded as inherent to the frontend (Koen et al. 2002; Sperry and Jetter 2009) is related to increasing the speed of information flow referred in the section above. However, there can be side-effects to reducing the NPD cycle time (either by king agile iteration and overlapping or otherwise shortening the time it takes). According to many studies, including those by Achiche et al. (2013), Carbone and Tippett (2014), and Love and Edwards (2013), whenever "Redo" and "Redirect" tasks or activities occur in the NPD cycle, the overall project time and cost commitments increase exponentially. Also, they argue that it is foolish to concentrate overly on shortening NPD time to launch products faster without properly conducting research and analysis from the perspective of the range, details, and amount of NPD-related data. Developing products based on poor quality product data incurs more risks than an extended NPD period in the FFE (Backman et al. 2007).

Therefore, it is crucial to consider how the agile NPD can be affected by the quality of information flow point of view (Strategy \#2). Namely, what if the actual number of iterations can be conspicuously decreased by way of reinforced capabilities in the quality of information flow? What if the efficiency of acquiring relevant data by screening irrelevant data can increase through setting up a high-performance database for information processing and knowledge accumulation? Rapid iterations might less longer become as necessary if fewer iterations are ultimately required. Such an approach can support to bring about agility. Besides, this approach is expected to interact internally to reduce ambiguity, considered to be one of the most critical issues in the initial design phase (Frishammar et al. 2011; Yoon and Jetter 2015) as it is significantly influenced by the quality of information.

Consequently, a new FFE model enabling agility can be realised by enhancing the quality of information flow as one of the alternatives to the previous approach.

\subsubsection{Strategy \#4: incremental and radical NPDs through contextualisation or conceptualisation}

Many experts on FFE, including Reinertsen (1994) and Smith and Reinertsen (1991), argue that a one-size-fits-all type is less longer feasible in many NPD conditions such as those with varied types of product lines (which are more relevant to incremental NPD), or those with newly added product families (which are much more related to radical NPD).

A suitable model for both NPD attributes can be structured by formulating a distinction between early or late activities in the initial design phase (Backman et al. 2007). This type of discrimination in the FFE is called "Contextualisation" and "Conceptualisation". "Contextualisation" is where the NPD-related data collection and analysis, which mainly occurs in the early parts of the FFE, are undertaken differently owing to contextual differences between incremental and radical NPD conditions. These contextual differences come from the intrinsic nature of the two NPD directions: incremental NPD has a tendency to rely more on finding out the problems in the previous products and thus develop additions-to-the-existing-product-line products by further utilising internal resources. Instead, radical NPD tends to be more inclined towards discovering new trends and thus develop new-to-the-company products through communication with external resources. The difference between these two tendencies are most apparent during the research and analysis portions of the initial design stage. On the other hand, structuring the variation in the late phase is referred to as "Conceptualisation". It aims to differentiate conceptual designs which are generally inserted into the initial actual NPD phase, divided into two groups, respectively, depending upon whether the NPD direction is more inclined to incremental or radical.

Valuable cues from the approach above can be obtained; different deployment of FFE activities and routes of information flow (in either the front or back part of the FFE) can result in different model structures. One possible method to actualise this cue can be a modularity approach. The approach enables at least two channels for incremental and radical NPD to be established in the new Model: M130 (Nobelius and Trygg 2002) and M165 (Backman et al. 2007) can be referenced here. Even though these two models have multiple routes in their structures which differ depending on the type of project being conducted (e.g., a business evaluation-driven or advanced engineering-driven), the approach to building diverse routes through modularisation can be applied to a new FFE model which incorporates the two NPD attributes.

In conclusion, an FFE model for dealing with both incremental and radical NPDs can be obtained by different arrangements of FFE activities in the front or back part of the FFE.

\subsubsection{Strategy \#5: explicitness and responsiveness by planned flexibility}

Many authors, including Andriopoulos and Lewis (2009), Backman et al. (2007), and Gurtner et al. (2016), recommend developing an appropriate model which balances 
"Explicitness" (which typically presents in sequential formalised structures) and "Responsiveness" (which normally shows in non-sequential flexible structures, e.g., a recursive, chaotic, spiral, and modular type). This is known as the "Twofold" or "Ambidexterity" type (Andriopoulos and Lewis 2009; Backman et al. 2007).

Neither characteristics can be overlooked, since both types each have their own advantages. The benefits of one structural type are the weaknesses of the other. An explicit structure is of help to stable executions, as it decreases fuzziness and reinforcing the systematic approach (Kim and Wilemon 2002a, b; Koen et al. 2001). This structure has benefits in that it is keenly aware of more explicit directions for only individual execution but for coordinate synthesis in given executions (Bonner et al. 2002; Tatikonda and Rosenthal 2000). On the other hand, a responsive structure which takes a critical stance on formal process control has merit for generating more creative results by allowing for discretion on specific performance methods and approaches of performers (Bonner et al. 2002; Tatikonda and Rosenthal 2000). A structure which can be flexibly changed is of help to exploring alternative opportunities, ideas, and concepts (Donaldson 2001; Stringer 2000).

These two approaches should thus be harmonised in the FFE based on the merits for a given objective. In harmonising the two characteristics, Khurana and Rosenthal (1998), Lynn and Akgun (1998), and Rice et al. (2001) argue that "Explicitness" is better for the overall structure rather than for sub-structures in the sense that flexible performance can be controlled through a formalised system by taking the benefits of both sides; referred to as "Planned Flexibility". They further argue that in the opposite, "Explicitness" in the substructures, there can occur many situations where the very advantages of "Explicitness" diminishes, even along with the merits of "Responsiveness".

\subsubsection{Strategy \#6: procedural structure with performative sub-structures}

Concerning the "Planned Flexibility" characteristic (Strategy \#5) suggested in the previous section, the procedural form, which tends to pursue to "Explicitness", can become the overall structure whose sub-structures can be of the performative form, which leaves room for flexibility; "Responsiveness". More in detail, 'Task' units can be arranged and constructed in a procedural manner to pursue "Explicitness", while 'Activity' units (which fall under 'Tasks' units) and 'Performance Method' and 'Toolkit' units (which are support systems to accomplish the aim and purposes of those 'Activity' units) can be structured in a performative manner to pursue "Responsiveness" (Strategies \#7-10). The model to reference here can be M033 (Hubka and Eder 1987, 1996), wherein each stage ('Task' units) of the model-oriented sequential structure serves as the 'Toolkit' unit itself, termed the "Technical System" (TS): outputs produced from activities of the previous task enter into activities of the next task as inputs, through the TS platform.

Consequently, one possible method to establish a balance between the procedural and performative structures considering the merits of "Planned Flexibility" is developing an FFE model using a procedural structure with performativetype sub-structures.

\subsection{Strategy dimension \#2: FFE performance structure}

\subsubsection{Strategy \#7: six main FFE tasks}

The FFE component can typically be made up of six essential tasks. These following six tasks are commonly referred to in most of the FFE models.

First, including of the opportunity identification (Task 1) and idea generation (Task 2) tasks in the FFE phase is inevitable to build a new FFE model. These two tasks can serve as vital parts wherein the system of the information processing and know accumulation can indeed be operated to equip the data-driven type (Strategy \#1). Many experts, including Alam (2003) and De Brentani and Reid (2012), have highlighted that information and knowledge processed in those two parts can serve as most crucial inputs to the actual NPD phase throughout the FFE. A database consisting of these pieces of information and knowledge can be built with outcomes obtained from those two parts affecting the progress and outcomes of actual NPD. The operation of those parts can indeed affect agile NPDs, enhancing the quality of information flow (Strategy \#2) in the data-driven system.

Next, the mission statement (Task 3 ) and requirements list (Task 4) tasks, as design briefs, are also crucial in building a new FFE model, The usable NPD-related data including actionable ideas or solutions, as knowledge assets, which have been filtered from the practicability point of view, produced in the data-driven system operated in the two previous tasks can be listed and arranged in these two tasks (Carbone and Tippett 2004; Jacoby and Scheelen 2012; Williams et al. 2007). As a result, those two tasks can be regarded as a sort of a project protocol, acting as an aggregate of an overall course map for actual NPD implementation phase (Cooper 1988; Jacoby and Scheelen 2012).

Finally, the conceptual design (Task 5) and prototyping (Task 6) tasks have been acknowledged as important since around the early 2000s with the "Manufacture-able Design" and "Design for Manufacturability" trend becoming popular (Barczak et al. 2009; Eveleens 2010; Verganti 2011). The conceptual design task aims to not only build a function and system structure but visualise the appearance 
of a target product, reflecting knowledge assets listed up in the requirement lists tasks across all corners of the target product (Cooper 1998; Khurana and Rosenthal 1998). In the case of the prototyping task, its primary purpose is to test and verify whether prototypes manufactured from those conceptual designs can be physically, functionally, and technically operated (Bacon et al. 1994; Clark and Fujimoto 1991). The more complex the products, the more prototyping and experiments are needed (Bacon et al. 1994; Clark and Fujimoto 1991). The experiment of prototypes in the initial design stage is becoming more essential, so that can be of help to obtaining rapid customer feedback which can be applied to fast improvements of the conceptual designs (Veryzer 2005; Zhang et al. 2001).

\subsubsection{Strategy \#8: activity}

It seems to be better for all core FFE activities required in the FFE to be structured in the model, from the viewpoints of deepening and extending the range of operating information flow in the data-driven system (Strategy \#1). Also, it seems to be better for the FFE activities to involve multiple functional domains to support concurrent collaboration (Strategy \#10). As a result, this can give a rise to reduction in uncertainty incurred by an insufficient quantity of NPDrelated data and in ambiguity triggered by an incorrect interpretation of those data.

\subsubsection{Strategy \#9 and \#10: performance method and toolkit for contextual performance and concurrent collaboration}

\section{Toolkit}

Toolkits need to be specific enough to enable performers to conduct the given task and activity with the minimum possible difficulty in terms of performance directions and methods (Sandmeier et al. 2004), within a reasonable range where performers can flexibly utilise their particular performance behaviours and approaches (Cooper 1988; van Aken 2005). It is difficult for all personnel participating in an NPD project to have a high degree of expertise either in a particular functional domain or multitude functional domains (Dane and Pratt 2007; Eling et al. 2014). According to Archer (1969), Cross (1993), and van Aken (2005), detailed toolkits which indicate detailed performance directions and mechanisms can relieve deviation in individual expertise and capabilities triggered by their different education background and levels of experience. It also helps if toolkits can prevent performers from carrying out particular work in incorrect ways.

Although many specific toolkits for FFE performance have been developed so far, however, only a few tool- kits have been developed with contextual performance and concurrent collaboration in mind. This means that the purpose, roles, and parameters of each toolkit (used in not only a single functional domain but also across multiple functional domains) cannot be inferred from parameters obtained from other toolkits. It is quite possible that results obtained from each toolkit have a tendency to be separate and exist independently, without an interrelationship between the results produced from other related toolkits. This gives rise to incomplete parameters caused by obtaining an insufficient quantity of parameters from missing the performance of essential toolkits, as well as an incorrect analysis of parameters from interpreting parameters fragmentarily. This results in increasing iterative modification work and associated time and cost commitments. In this regard, development of toolkit sets which can compensate for the defects above is required, with the following five strategies.

First, toolkits can be developed for contextual performance (which is generally activated in a single functional domain). Bacon et al. (1994), Khurana and Rosenthal (1997), and Simms (2012) have also emphasised this kind of development direction to some degree in their studies. Toolkits can be systematically interlinked with each other, with consideration of the purpose and roles of each toolkit and their relationships. To clarify, outputs obtained from the previous toolkits can flow into the inputs of the subsequent toolkit, i.e., where data come from and where those data goes, in a contextual relationship of a single functional domain.

Second, toolkits devised from the contextual performance aspect can be realised for concurrent collaboration (which is typically fostered in multi-functional domains). The toolkits can be functionally and structurally embodied for simultaneous collaboration. One possible approach is that the structure for concurrent collaborative toolkit sets can be constructed by detecting the points of contact between each toolkit and connecting them. These points of contact can be observed by figuring out which toolkits have the similar purpose and roles and what the similar characteristics of inputs and outputs produced in each toolkit are. Simultaneous collaborative toolkit sets can make up for deficiencies in organisations which have difficulties with 'T-type', 'TT-type', and 'TTT-type' 'Multi Knowledgeable' performers skilled in multiple NPD domains (Eling et al. 2014; Griffin et al. 2009; Part et al. 2009).

Third, toolkits structured from the two aspects above can be considered to process qualitative data rather than quantitative data. FFE data tend to be qualitative data rather than quantifiable due to the intrinsic nature of the FFE which have uncertainty and ambiguity to a significant degree (Jetter 2003). Hence, Achiche et al. (2013) 
and Lin and Chen (2004) contend that typical toolkits, which primarily use the conventional quantitative techniques and mathematical and economic approaches, can have a high possibility to reveal limitations in their ability to manage data produced from the FFE phase. In this regard, the consideration of which format is more appropriate for dealing with values which are less relevant to numerical but more related to textual and narrative in nature is needed in physicalising the form of the toolkits.

Fourth, when structuring toolkit sets using the three aspects above, it is important to address the pursuit of both "Explicitness" and Responsiveness" characteristics (Strategy \#5). According to Cooper (1983) and van Aken (2005), toolkit sets should not provide too many rules and regulations which can hinder creative performance behaviours of performers, although it is indisputable that those should be detailed enough to serve as useful instructive action guides for performers. Toolkits can explicitly give directions to deal with NPD-related parameters, and it is better to leave room for selecting optional methods or techniques when using the given toolkits. To realise this suggestion, one possible approach, a mixed method of "Rational Analysis Approach" and "Use of Intuition" which were studied by Eling et al. (2014), can be utilised. The development of toolkit sets can consider both: 1) how to enable performers to conduct their FFE performance in more scientific and rational ways under stable control (using the "Rational Analysis Approach"), and 2) how to increase their creative performance behaviour under further flexible control (using the "Use of Intuition'). The former can be made possible by not only devising toolkit sets for contextual performance and concurrent collaboration but functional and structural constructing of those toolkit sets into an overall architecture of the model, to provide explicit directions to handle parameters. The latter can be feasible by leaving room for selecting optional methods or techniques when using each given toolkit. For instance, a particular toolkit is robustly structured with a systematic process for the product usage process study activity in the opportunity identification task. In this, detailed skills involved in that activity, such as video-recording for the order of users' action, cultural probing, and ethnography, can be left to the discretion of the performers concerned.

Fifth, how to construct those toolkit sets devised from the aspects above into the model structure needs to be determined. This relates to developing a model for the procedural form with performative-type sub-structures (Strategy \#6). One of the possible solutions is that substructures can consist of those toolkit sets whose type can accelerate performance, while the overall structure (the fundamental architecture of the whole model) can have a phased form. This means that toolkit sets are not merely provided with the model, but are incorporated into the model itself, as integral components. Even if toolkit sets are appropriately built for the contextual performance and concurrent collaboration, if they are not well harmonised with the given model, those sets will be still lacking from the performance structure and its operating mechanism standpoint.

2. Performance method

In the case of providing performance methods, a manual, step-by-step instruction guide on how the toolkit is to be used can be resources. This does not seems to essentially require specific instructions and detailed methods to be integrated into the model, since it is expected that the format and structure of toolkits devised from the above four aspects can serve as intuitive guidance.

\subsection{A summary of strategies for a new FFE model development}

Table 18 shows a summary of new FFE model development strategies built according to each criterion based on the analysis.

It is noteworthy that such strategies do not exist independently, but instead have a strong possibility to influence each other. This is beneficial for applying many variables and various constrains to a new FFE model development in a less complicated way. Namely, as shown in Fig. 18, the strategies exert influence on the form of the cluster network; chain-reaction effect.

First, the development of the data-driven FFE model (Strategy \#2) can be related to a deployment of toolkits which considers contextual performance and concurrent collaboration (Strategy \#10) in the performative structure (Strategy \#6). The arrangement wherein input and output parameters are linked to each other for contextual performance and concurrent collaboration can align with the operation mechanism of the data-driven model in which data are encoded and decoded in the information processing system. The parameters processed can also be in line with the information processing system of the data-driven model that pursues the transition of "Factual" data into usable "Value" as knowledge assets.

Next, the data-driven model in which the information processing system is equipped to increase the quality of information flow (Strategy \#2) can help realise agile NPD (Strategy \#3). Increased efficiencies in the quality of information flow can contribute to reducing iterative works themselves which are typically regarded as inherent to the FFE stage, which can lead to another approach to materialise agility.

The construction of hierarchical FFE units consisting of 'Task', 'Activity', 'Performance Method', and 'Toolkit' 
Table 18 Strategies for new FFE model development

\begin{tabular}{|c|c|c|c|}
\hline Dimension & \# & Criterion & Strategy \\
\hline \multirow{6}{*}{$\begin{array}{l}\text { The first } \\
\text { dimension:overall } \\
\text { attribute }\end{array}$} & 1 & $\begin{array}{l}\text { Study } \\
\text { Taxonomy }\end{array}$ & Diverse studies intensively concentrating on the FFE are required \\
\hline & 2 & $\begin{array}{l}\text { Model } \\
\text { Type }\end{array}$ & $\begin{array}{l}\text { A data-driven type can be created by augmenting "Information Processing" and "Knowledge Accu- } \\
\text { mulation", from the viewpoint of transiting "Factual" to "Value" data }\end{array}$ \\
\hline & 3 & $\begin{array}{l}\text { NPD } \\
\text { Speed }\end{array}$ & $\begin{array}{l}\text { Agile development can be realised by focusing on the "Quality of Information Processing" capabili- } \\
\text { ties, to reduce iterative works themselves }\end{array}$ \\
\hline & 4 & $\begin{array}{l}\text { NPD } \\
\text { Attribute }\end{array}$ & $\begin{array}{l}\text { A model that aims at balancing both incremental and radical NPDs can be developed through different } \\
\text { deployments of FFE activities in the front sections and back sections of the FFE, using the "Contex- } \\
\text { tualisation" and "Conceptualisation" theories }\end{array}$ \\
\hline & 5 & $\begin{array}{l}\text { Model } \\
\text { Characteristics }\end{array}$ & $\begin{array}{l}\text { An overall characteristic can be designed based on "Explicitness" in the pursuit of stable operations, } \\
\text { e.g., phased and formalised process, while "Responsiveness" can support sub-structures in the pur- } \\
\text { suit of creative behaviour, e.g., a modular or spiral process, using "Planned Creativity" } \\
\text { By leaving room for performers to select optional performance methods and techniques (to foster } \\
\text { creative behaviour) in each formalised performance structure (to control performance directions), } \\
\text { "Explicitness" and "Responsiveness" characteristics can be balanced }\end{array}$ \\
\hline & 6 & $\begin{array}{l}\text { Model } \\
\text { Structure }\end{array}$ & A model can be built with a procedural structure with performative-type sub-structures \\
\hline \multirow{4}{*}{$\begin{array}{l}\text { The second dimen- } \\
\text { sion: perfor- } \\
\text { mance structure }\end{array}$} & 7 & $\begin{array}{l}\text { FFE } \\
\text { Task }\end{array}$ & $\begin{array}{l}\text { The six main FFE tasks are: the opportunity identification, idea generation, requirements list, mission } \\
\text { statement, conceptual design, and prototyping tasks }\end{array}$ \\
\hline & 8 & $\begin{array}{l}\text { FFE } \\
\text { Activity }\end{array}$ & Each FFE task needs essential FFE activities which involves diverse functional domains \\
\hline & 9 & $\begin{array}{l}\text { FFE } \\
\text { Performance } \\
\text { Method }\end{array}$ & $\begin{array}{l}\text { Performance methods can serve as underlying resources for the functional and structural embodiment } \\
\text { of toolkits }\end{array}$ \\
\hline & 10 & $\begin{array}{l}\text { FFE } \\
\text { Toolkit }\end{array}$ & $\begin{array}{l}\text { Toolkits need to be specific enough to enable performers to conduct the given task and activity with } \\
\text { the minimum possible difficulty in terms of performance directions and methods, within a rea- } \\
\text { sonable range where performers can flexibly utilise their particular performance behaviours and } \\
\text { approaches, using both "Rational Analysis Approach" and "Use of Intuition Approach" } \\
\text { Toolkits can be developed with consideration of contextual performance and concurrent collaboration } \\
\text { Toolkits are appropriate for dealing with qualitative data processing } \\
\text { Toolkits can leave room for performers to choose optional performance methods and techniques (to } \\
\text { foster creative behaviour; "Responsiveness") in each formalised toolkit structure (to control perfor- } \\
\text { mance directions; "Explicitness") } \\
\text { Toolkits using the above three considerations can be well incorporated into the model structure }\end{array}$ \\
\hline
\end{tabular}

(Strategies \#7-10) can have a strong interrelationship with model characteristics regarding "Explicitness" and "Responsiveness" characteristics (Strategy \#5). The structure of those units can affect the model structure divided into procedural and performative types (Strategy \#6). Concerning "Planned Flexibility" (Strategy \#5), 'Task' units can be structured in a procedural manner to pursue "Explicitness", while 'Activity' units (which are subordinated to 'Tasks' units) and 'Performance Method' and 'Toolkit' units (which are support systems to conduct those activities) can be structured in a performative manner to pursue "Responsiveness". The 'Toolkit' units arranged for contextual performance can provide a procedure for performing each toolkit, so that it can also contribute to building the procedural structure. Furthermore, the entire frame of each toolkit can be formalised to provide explicit performance directions and operating mechanisms from the viewpoints of "Explicitness" characteristic. "Responsiveness" can be embodied by offering discretion to select optional methods and techniques when using each toolkit.

Finally, the model type that targets both incremental and radical NPDs (Strategy \#4) affects the placements of activities in the front or back part of the FFE phase (Strategy \#8), building two different channels for those two different NPD attributes.

The possibility of a correlation between different model development strategies has been defined. Those correlations were not directly revealed in the analysis of the previous 266 FFE studies as factual correlations, but newly intended correlations established for one of the possible applications to a new FFE model development. 


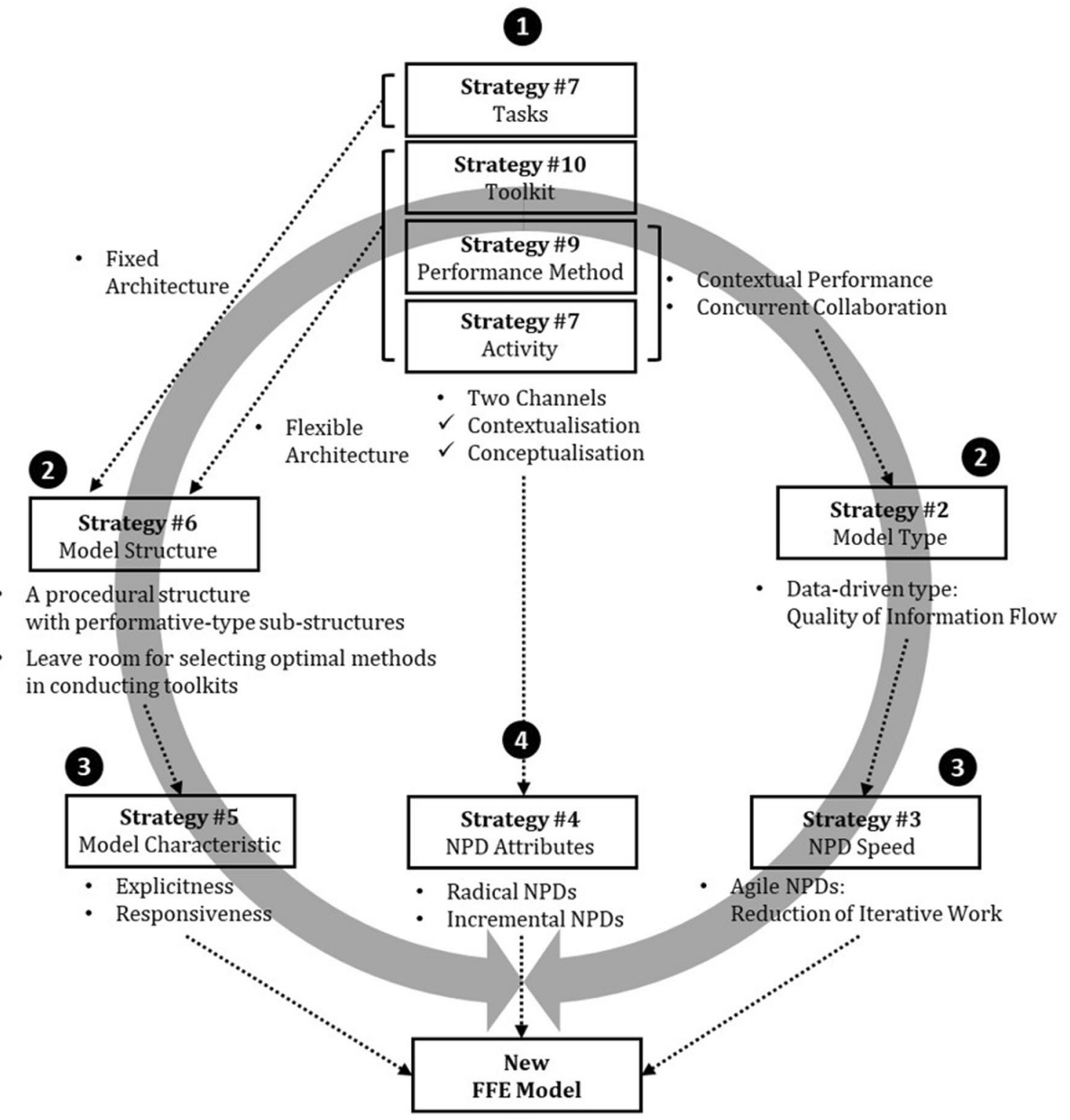

5

Fig. 18 Correlation of new FFE model development strategies

\section{Conclusion: a summary and its contributions}

This study has examined 266 existing studies on the FFE. These were chosen via an eight-phase study selection process using a "Bibliometrics" method and analysed statistically and chronologically with ten criteria categorised into two main dimensions, an overall FFE attributes and FFE performance structure. Per each criterion, FFE study evolution trends and features and helpful knowledge and theories of each FFE study have been identified. For each of the criteria, an FFE model development strategy has been formulated with proposed executing option using chainreaction effect. The details of the expected contributions of this paper, along with the ICL data repository document, are outlined as follows:

- It is the first study to examine over 200 (266) FFE studies, with ten specific criteria, whereas the previous studies investigated less than 20 FFE studies. Furthermore, while there are many studies examining the whole range of product innovation processes, there are few studies intensively investigating the FFE component.

- To contribute to an overview of previous FFE studies. 
- To comprehend FFE study trend changes regarding evolve or fade. Particularly, trend changes for each appraisal criterion can be grasped by tracking values which change along each vertical axis.

- To understand the features of each FFE study and associated knowledge and theories. Particularly, features of each FFE study can be explored by tracking values shown in each horizontal axis.

- To support a comparative analysis between each FFE study in term of the development trends, features, knowledge, and theories involved.

- To select each FFE study which need to be examined in different future research. The database in the ICL repository could be expanded and strengthened by adding the results of future studies on the FFE.

- To support the creation of application strategies of a new FFE model development.

- To understand theories associated with the application of the FFE model development strategies, e.g., the information processing theory (the speed and quality of information processing) and the knowledge accumulation theory.

- To guide the processing of two crucial factors; 1) the overall attributes and outcomes of the FFE affect the entirety of the innovation process and 2) the performance structure related to processing parameters.

To conclude, this paper and the data in the ICL repository, as a useful database on FFE studies, can be of help to coming up with new FFE model development strategies by understanding the features of existing FFE studies as well as, in general, to gain relevant knowledge and theories and to understand trend evolutions in FFE studies.

\section{Limitations and future research direction}

First, not all product innovation process can be gathered and analysed in this study: more than 600 product innovation processes had been reported by the early 2010s. Even though around 260 FFE studies were gathered in this study using a systematic literature review method, a few studies having significant contributions on FFE sectors might have been omitted. In future research, the FFE studies' database will be reinforced continuously.

Second, significant specific criteria for analysing the FFE studies were set up systematically. Those criteria were derived and divided into two dimensions which make the FFE weakest as well as crucial. The former dimension is related to overall attributes of FFE, while the latter is associated with the FFE performance structures which relate to processing parameters. The six criteria comprised of the former dimension were frequently defined in recent conferences. For criteria 7-10, the basic constituents making up the FFE performance structure were defined. However, different criteria can be set up in future research to strengthen the database.

Third, a rigour and robust process was used to gather FFE studies (a total of eight steps). The number of studies collected at each of eight steps could be specified in future studies to increase the validity of the data collection method.

Funding Not applicable.

Data availability Subject area: Fuzzy Front End (FFE) studies. Type of data: Table (Chart) with texts, number, and symbols. How data were required: literature review (Web of Science). Data format: Dataset in the Imperial College London Research Repository. Data source location: Imperial College London, London, United Kingdom.

Data accessibility:

With the paper,

Repository name: Imperial College London (ICL) Research Data Repository. Data identification number: https://doi.org/10.14469/hpc/ 7725. Direct URL to data: http://doi.org/10.14469/hpc/7725. (The URL address is also found in the manuscript).

Data description:

Data set

Appraisal criteria for 266 FFE studies. Analysis table of FFE studies. A list of FFE studies.

Code availability Not applicable.

\section{Declarations}

Conflict of interest The authors declare that they have no known competing financial interests or personal relationships that could have influenced the work reported in this paper.

Open Access This article is licensed under a Creative Commons Attribution 4.0 International License, which permits use, sharing, adaptation, distribution and reproduction in any medium or format, as long as you give appropriate credit to the original author(s) and the source, provide a link to the Creative Commons licence, and indicate if changes were made. The images or other third party material in this article are included in the article's Creative Commons licence, unless indicated otherwise in a credit line to the material. If material is not included in the article's Creative Commons licence and your intended use is not permitted by statutory regulation or exceeds the permitted use, you will need to obtain permission directly from the copyright holder. To view a copy of this licence, visit http://creativecommons.org/licenses/by/4.0/.

\section{References}

Achiche S, Appio FP, McAloone TC, Di Minin A (2013) Fuzzy decision support for tools selection in the core front end activities of new product development. Res Eng Design 24:1-18

Agouridas V, McKay A, Winand H, de Pennington A (2008) Advanced product planning: a comprehensive process for systemic definition of new product requirements. Requirements Eng 13:19-48

Akbar H, Tzokas N (2013) Charting the organisational knowledgecreation process: an innovation-process perspective. J Mark Manag 29:1592-1608 
Alam I (2006a) Removing the fuzziness from the fuzzy front-end of service innovations through customer interaction. Ind Mark Manage $35: 468-480$

Alam I (2006b) Removing the fuzziness from the fuzzy front-end of service innovations through customer interactions. Ind Mark Manage 35:468-480

Al-Hakim L, Kusiak A, Mathew J (2000) A graph-theoretic approach to conceptual design with functional perspectives. Comput Aided Des 32:867-875

Andreasen MM, Hein L (2000) Integrated product development. Springer

Andriopoulos C, Lewis MW (2009) Exploitation-exploration tensions and organizational ambidexterity: Managing paradoxes of innovation. Organ Sci 20:696-717

Archer LB (1969) Systematic method for designers: technological innovation: a methodology. Council Indust Design 1:19-23

Armbrecht FR Jr et al (2001) Knowledge management in research and development. Res Technol Manag 3:28-48

Bacciotti D, Borgianni Y, Cascini G, Rotini F (2016) Product Planning techniques: investigating the differences between research trajectories and industry expectations. Res Eng Design 27(4):367-389

Backman M, Börjesson S, Setterberg S (2007) Working with concepts in the fuzzy front end: exploring the context for innovation for different types of concepts at Volvo Cars. R\&D Management 37:17-28

Bacon G, Beckman S, Mowery D, Wilson E (1994) Managing product definition in high-technology industries: a pilot study. Calif Manage Rev 36:32-56

Barczak G, Griffin A, Kahn KB (2009) Perspective: trends and drivers of success in NPD practices: results of the 2003 PDMA best practices study. J Prod Innov Manag 26:3-23

Baumgartner H, Pieters R (2003) The structural influence of marketing journals: a citation analysis of the discipline and its subareas over time. J Mark 67:123-139

Bhattacharya S, Krishnan V, Mahajan V (1998) Managing new product definition in highly dynamic environments. Manage Sci 44:S50-S64

Biemans W, Griffin A, Moenaert R (2007) Twenty years of the Journal of product innovation management: History, participants, and knowledge stock and flows. J Prod Innov Manag 24:193-213

Birkhofer H, Kloberdanz H, Berger B, Sauer T (2002) Cleaning up design methods-describing methods completely and standardised. In: DS 30: Proceedings of DESIGN 2002, the 7th International Design Conference, Dubrovnik, 2002.

Bonner JM, Ruekert RW, Walker OC Jr (2002) Upper management control of new product development projects and project performance. J Prod Innov Manag 19:233-245

Borgianni Y, Cascini G, Rontini F (2018) Investigating the future of the fuzzy front end: towards a change of paradigm in the very early design phases? J Eng Des 29(11):644-664

Boulding W, Christen M (2003) Sustainable pioneering advantage? Profit implications of market entry order. Mark Sci 22:371-392

Brentani DEU, Reid SE (2012) The fuzzy front-end of discontinuous innovation: insights for research and management. J Product Innov Manag 29:70-87. https://doi.org/10.1111/j.1540-5885. 2011.00879.x

Bruce M, Bessant JR (2002) Design in business: Strategic innovation through design. Pearson Educ 2:34-65

Brun E, Saetre AS (2008) Ambiguity reduction in new product development projects. Int J Innov Manag 12:573-596

Brun E, Steinar Saetre A, Gjelsvik M (2009) Classification of ambiguity in new product development projects. Eur J Innov Manag $12: 62-85$

Buijs J (2003) Modelling product innovation processes, from linear logic to circular chaos. Creativity Innov Manag 12:76-93
Carbone TA, Tippett DD (2014) The front end of product development and the impact on project success. International Project Management Association

Carvalho M, Fleury A, Lopes AP (2013) An overview of the literature on technology roadmapping (TRM): contributions and trends. Technol Forecast Soc Chang 80:1418-1437

Cascini G, Rotini F, Russo D (2011) Networks of trends: systematic definition of evolutionary scenarios. Proc Eng 9:355-367

Castilho J, Dias J, Bagno RB, Freitas JS, Cheng LC. A methodology to build an initial R\&D portfolio for industry-university cooperation. In: Management of Engineering and Technology (PICMET), 2015 Portland International Conference on, 2015. IEEE, pp 257-269.

Cavallucci D, Weill RD (2001) Integrating Altshuller's development laws for technical systems into the design process. CIRP Ann Manuf Technol 50:115-120

Chang SL, Chen CY, Wey SC (2007) Conceptualizing, assessing, and managing front-end fuzziness in innovation/NPD projects. R\&D Management 37:469-478

Chen J, Gao J (2005) The influence of fuzzy front end on innovation performance of complex product systems. Chinese J Manag 3:005

Chenglong Y, Fanrang K (2005) Study on inovation and management for fuzzy front end of product design. Sci Res Manag 26:19-23

Christiansen JK, Gasparin M (2017) How experiments in the fuzzy front end using prototyping generates new options. CERN Idea Square J Exp Innov 1:35

Clark KB, Fujimoto T (1991) Product development performance: strategy, organization, and management in the world auto industry. Harvard Business Press

Clarkson P, Coleman R, Hosking I, Waller S (2007) Inclusive design toolkit: engineering design centre. University of Cambridge

Clarkson PJ, Coleman R, Keates S, Lebbon C (2013) Inclusive design: design for the whole population. Springer

Conway S, Steward F (2009) Managing and shaping innovation. Oxford University Press

Cook DJ, Mulrow CD, Haynes RB (1997) Systematic reviews: synthesis of best evidence for clinical decisions. Ann Intern Med 126:376-380

Cooper RG (1983) A process model for industrial new product development. IEEE Trans Eng Manag 3:2-11

Cooper RG (1988) Predevelopment activities determine new product success. Ind Mark Manage 17:237-247

Cooper RG (1990) Stage-gate systems: a new tool for managing new products. Bus Horiz 33:44-54

Cooper RG (2008) Perspective: The stage-gate ${ }^{\circ}$ idea-to-launch process-update, what's new, and nexgen systems. J Prod Innov Manag 25:213-232

Cooper RG (2014) What's Next?: After Stage-Gate. Res Technol Manag 57:20-31

Cooper RG, Edgett SJ (2008) Maximizing productivity in product innovation. Res Technol Manag 51:47-58

Cooper RG, Sommer AF (2018) Agile-stage-gate for manufacturers: changing the way new products are developed integrating agile project management methods into a Stage-Gate system offers both opportunities and challenges. Res Technol Manag 61:17-26

Costa MAB, Toledo JC (2016) Analysis of predevelopment models and activities: a systematic bibliographic review. Gestão Produção 23(4):704-717

Cross N (1993) Science and design methodology: a review. Res Eng Design 5:63-69

Dahan E, Mendelson H (2001) An extreme-value model of concept testing. Manage Sci 47:102-116

Dane E, Pratt MG (2007) Exploring intuition and its role in managerial decision making. Acad Manag Rev 32:33-54 
De Bellis N (2009) Bibliometrics and citation analysis: from the science citation index to cybermetrics. Scarecrow press

Dershin H (2010) A framework for managing innovation. Internat J Bus Innov Res 4:598-613

Dewulf K (2013) Sustainable product innovation: the importance of the front-end stage in the innovation process. Advances in Industrial Design Engineering, edited by DA Coelho.

Donaldson L (2001) The contingency theory of organizations. Sage Publishers

Dröge C, Calantone R, Harmancioglu N (2008) New product success: is it really controllable by managers in highly turbulent environments? J Prod Innov Manag 25(3):272-286

Du Chatenier E, Verstegen JA, Biemans HJ, Mulder M, Omta O (2009) The challenges of collaborative knowledge creation in open innovation teams. Hum Resour Dev Rev 8:350-381

Durisin B, Calabretta G, Parmeggiani V (2010) The intellectual structure of product innovation research: a bibliometric study of the journal of product innovation management, 1984-2004. J Prod Innov Manag 27:437-445

Eling K, Griffin A, Langerak F (2014) Using intuition in fuzzy frontend decision-making: a conceptual framework. J Prod Innov Manag 31:956-972

El-Sayed ME (2008) Rethinking the Automotive Design and Development Processes for Product Realization. SAE Technical Paper.

Ester V-J, Daniel J (2007) Use of tools, methods and techniques during the fuzzy front end of innovation: their impact on innovation performance-an exploratory study of companies in the basque country guidelines for a decision support method adapted to NPD processes. In proceedings of ICED 2007, the 16th international conference on engineering design, Paris, France. pp 183-184.

Evanschitzky H, Eisend M, Calantone RJ, Jiang Y (2012) Success factors of product innovation: an updated meta-analysis. J Prod Innov Manag 29:21-37

Evbuomwan N, Sivaloganathan S, Jebb A (1996) A survey of design philosophies, models, methods and systems Proceedings of the Institution of Mechanical Engineers. J Eng Manuf 210:301-320.

Eveleens C (2010) Innovation management; a literature review of innovation process models and their implications. Science 800:900

Herstatt C, Verworn B (2001) The "fuzzy front end" of innovation. Working Papers/Technologie-und Innovationsmanagement. Technische Universität Hamburg-Harburg

Fairlie-Clarke T, Muller M (2003) An activity model of the product development process. J Eng Des 14:247-272

Frishammar J, Florén H, Wincent J (2011) Beyond managing uncertainty: insights from studying equivocality in the fuzzy front end of product and process innovation projects. IEEE Trans Eng Manage 58:551-563

Genc S, Messler RW, Gabriele GA (2000) A method for attachment design concept development in integral snap-fit assemblies. J Mech Des 122:257-264

Goldenberg J, Mazursky D, Solomon S (1999) Toward identifying the inventive templates of new products: a channelled ideation. $\mathrm{J}$ Mark Res 36:200-210

Goodman RA, Lawless MW (1994) Technology and strategy: conceptual models and diagnostics. Oxford University Press on Demand

Goto S, Ishida S, Gemba K, Yaegashi K (2014) The interaction between design research and technological research in manufacturing firm smart manufacturing innovation and transformation. Interconnect Intel 1:226

Griffin A (1997) PDMA research on new product development practices: updating trends and benchmarking best practices. J Prod Innov Manag 14:429-458

Griffin A, Price RL, Maloney MM, Vojak BA, Sim EW (2009) Voices from the field: how exceptional electronic industrial innovators innovate. J Prod Innov Manag 26:222-240
Griffiths-Hemans J, Grover R (2006) Setting the stage for creative new products: investigating the idea fruition process. J Acad Mark Sci 34:27-39

Gurtner S, Reinhardt R (2016) Ambidextrous idea generation-antecedents and outcomes. J Prod Innov Manag 33:34-54

Heising W (2012) The integration of ideation and project portfolio management-A key factor for sustainable success. Int J Project Manage 30:582-595

Howard TJ et al (2008) Describing the creative design process by the integration of engineering design and cognitive psychology literature. Des Stud 29(2):160-180

Hubka V, Eder WE (1987) A scientific approach to engineering design. Des Stud 8:123-137

Hubka V, Eder WE (1996) Design science: introduction to needs, scope and organization of engineering design knowledge. Springer

Hüsig S, Kohn S (2003) Factors influencing the front end of the innovation process: a comprehensive review of selected empirical NPD and explorative FFE studies Proceedings of the 10th IPDMC:14.

Hyung-Jin Park M, Lim JW, Birnbaum-More PH (2009) The effect of multiknowledge individuals on performance in cross-functional new product development teams. J Prod Innov Manag 26:86-96

Ito Y, Shinno H, Nakanishi S (1989) Designer's thinking pattern in the basic layout design procedure of machine tools-validity evaluation of thinking block. CIRP Ann Manuf Technol 38:141-144

Jacoby A (2012) Performance in the Front-end of Innovation: linking strategy to requirements. University of Antwerp

Jacoby A, Scheelen L (2012) How to prepare students for the real front-end of innovation challenges: a methodological perspective. In: DS 74: proceedings of the 14th international conference on engineering and product design education (E\&PDE12) design education for future wellbeing, Antwerp, Belguim, 06-07.9.

Jetter AJ (2003) Educating the guess: strategies, concepts and tools for the fuzzy front end of product development. In: management of engineering and technology, 2003. PICMET'03. technology management for reshaping the world. Portland International Conference on, IEEE, pp 261-273.

Kerin RA, Varadarajan PR, Peterson RA (1992) First-mover advantage: a synthesis, conceptual framework, and research propositions. J Market 3:33-52

Khurana A, Rosenthal SR (1997) Integrating the fuzzy front end of new product development. IEEE Trans Eng Manage 25:35-49

Khurana A, Rosenthal SR (1998) Towards holistic "front ends" in new product development. J Prod Innov Manag 15:57-74

Kim K-Y, Kim YS (2011) Causal design knowledge: alternative representation method for product development knowledge management. Comput Aided Des 43:1137-1153

Kim J, Wilemon D (2002a) Focusing the fuzzy front-end in new product development. R\&D Manag 32:269-279

Kim J, Wilemon D (2002b) Strategic issues in managing innovation's fuzzy front-end. Eur J Innov Manag 5:27-39

Kim J, Wilemon D (2010) Accelerating the fuzzy front-end of NPD projects: methods and management. Int J Eng Manag Econ 1:80-101

Kock A, Heising W, Gemünden HG (2015) How ideation portfolio management influences front-end success. J Prod Innov Manag 32:539-555

Koen PA et al (2001) Providing clarity and a common language to the "fuzzy front end." Res Technol Manag 44:46-55

Koen PA et al (2002) Fuzzy front end: effective methods, tools, and techniques. PDMA Tool Book 1:5-35

Kumar V (2012) 101 design methods: a structured approach for driving innovation in your organization. John Wiley and Sons

Kurkkio M (2011) Managing the fuzzy front-end: insights from process firms. Eur J Innov Manag 14:252-269 
Kutvonen A, Torkkeli MT (2009) Opening the fuzzy front end: a synthesis of two theories. In: management of engineering \& technology. PICMET 2009. Portland international conference on, 2009. IEEE, pp 2029-2036.

Langerak F, Hultink EJ (2005) The impact of new product development acceleration approaches on speed and profitability: Lessons for pioneers and fast followers. IEEE Trans Eng Manage 52:30-42

Langerak F, Jan Hultink E, Robben HS (2004) The role of predevelopment activities in the relationship between market orientation and performance. R\&D Manage 34:295-309

Laswell HD (1948) The structure and function of communication in society. Commun Ideas 37:215-228

Lawson K, Finkelstein A (2002) Integration of product and technology development process with $R \& D$ portfolio management using efficient frontier analysis. In: Engineering Management Conference, 2002. IEMC'02. 2002 IEEE International, IEEE, pp 143-147.

Leenders RTA, Van Engelen JM, Kratzer J (2003) Virtuality, communication, and new product team creativity: a social network perspective. J Eng Tech Manage 20:69-92

Li G, Tan R, Liu Z, Zhang H (2006) Idea generation for fuzzy front end using TRIZ and TOC. In: 2006 IEEE International Conference on Management of Innovation and Technology, IEEE, pp 590-594.

Lidwell W, Holden K, Butler J (2010) Universal principles of design, revised and updated: 125 ways to enhance usability, influence perception, increase appeal, make better design decisions, and teach through design. Rockport Publishers

Lin CT, Chen CT (2004) A fuzzy-logic-based approach for new product Go/NoGo decision at the front end. IEEE Trans Syst Man Cyber Syst Hum 34:132-142

Love PE, Edwards DJ (2013) Curbing rework in offshore projects: systemic classification of risks with dialogue and narratives. Struct Infrastruct Eng 9:1118-1135

Luchs M, Swan KS (2011) Perspective: The emergence of product design as a field of marketing inquiry. J Prod Innov Manag 28:327-345

Lukas BA, Menon A (2004) New product quality: intended and unintended consequences of new product development speed. J Bus Res 57:1258-1264

Lynn GS, Akgün AE (1998) Innovation strategies under uncertainty: a contingency approach for new product development. Eng Manag J 10:11-18

Lynn GS, Schnaars SP, Skov RB (1999) A survey of new product forecasting practices in industrial high technology and low technology businesses. Ind Mark Manage 28:565-571

Markham SK (2013) The impact of front-end innovation activities on product performance. J Prod Innov Manag 30:77-92

McCarthy IP, Tsinopoulos C, Allen P, Rose-Anderssen C (2006) New product development as a complex adaptive system of decisions. J Prod Innov Manag 23:437-456

McKay A, de Pennington A, Baxter J (2001) Requirements management: a representation scheme for product specifications. Comput Aided Des 33:511-520

Meade N, Islam T (2006) Modelling and forecasting the diffusion of innovation-A 25-year review. Int J Forecast 22:519-545

Mendes GH, Oliveira MG (2015) Bibliometric analysis of the front-end of innovation. In: management of engineering and technology (PICMET), 2015 Portland international conference on, IEEE, pp 648-66.

Michael B (2008) Product strategy and management. Pearson Educ India 6:10-23

Millson MR, Raj S, Wilemon D (1992) A survey of major approaches for accelerating new product development. J Prod Innov Manag 9:53-69

Montagna F (2011) Decision-aiding tools in innovative product development contexts. Res Eng Design 22:63-86
Montoya-Weiss MM, O’Driscoll TM (2000) From experience: applying performance support technology in the fuzzy front end. J Prod Innov Manag 17:143-161

Nobelius D, Trygg L (2002) Stop chasing the front end process-management of the early phases in product development projects. Int J Project Manage 20:331-340

O'Connor P (1995) Total quality development: a step-by-step guide to world class concurrent engineering, don clausing, ASME press, 1994. Qual Reliab Eng Int 11(3):224-224

Oconnor GC, Rice MP (2001) Opportunity recognition and breakthrough innovation in large established firms. Calif Manag Rev 43:95-116

Ogr I (2013) Human Centred Design Toolkit. IDEO, London

Okubo Y (1997) Bibliometric indicators and analysis of research systems: methods and examples. OECD Publishing

Oliveira MG, Rozenfeld H (2010) Integrating technology roadmapping and portfolio management at the front-end of new product development. Technol Forecast Soc Chang 77:1339-1354

Osteras T, Murthy D, Rausand M (2006) Product performance and specification in new product development. J Eng Des $17: 177-192$

Ottum BD, Moore WL (1997) The role of market information in new product success/failure. J Prod Innov Manag 14:258-273

Ozer M (2007) Reducing the demand uncertainties at the fuzzy-frontend of developing new online services. Res Policy 36:1372-1387

Pahl G, Beitz W, Feldhusen J (2007) Grote engineering design. Springer

Phaal R, Farrukh CJ, Probert DR (2004) Technology roadmapping-a planning framework for evolution and revolution. Technol Forecast Soc Chang 71:5-26

Poskela J, Martinsuo M (2009) Management control and strategic renewal in the front end of innovation. J Prod Innov Manag 26:671-684

Prasad B (1996) Concurrent engineering fundamentals, vol 1. Prentice Hall Englewood Cliffs

Prasad B (2000) A concurrent function deployment technique for a workgroup-based engineering design process. J Eng Des 11:103-119

Prasad B, Wang F, Deng H (1998) A concurrent workflow management process for integrated product development. J Eng Des 9:3

Press M, Cooper R (2017) The design experience: the role of design and designers in the twenty-first century. Routledge

Pugh S (1991) Total design: integrated methods for successful product engineering. Addison-Wesley

Ramos-Rodríguez AR, Ruíz-Navarro J (2004) Changes in the intellectual structure of strategic management research: a bibliometric study of the Strategic Management Journal, 1980-2000. Strateg Manag J 25:981-1004

Reid SE, De Brentani U (2004) The fuzzy front end of new product development for discontinuous innovations: a theoretical model. J Prod Innov Manag 21:170-184

Reim W, Parida V, Örtqvist D (2015) Product-Service Systems (PSS) business models and tactics-a systematic literature review. J Clean Prod 97:61-75

Reinertsen DG (1994) Streamlining the fuzzy front-end. World Class Design Manuf 1:4-8

Reinertsen DG, Smith PG (1991) The strategist's role in shortening product development. J Bus Strateg 12:18-22

Rice M, Kelley D, Peters L, Colarelli O'Connor G (2001) Radical innovation: triggering initiation of opportunity recognition and evaluation. R\&D Management 31:409-420

Riel A, Neumann M, Tichkiewitch S (2013) Structuring the early fuzzy front-end to manage ideation for new product development. CIRP Ann Manuf Technol 62:107-110

Roach DC (2020) Is it time to reassess the front-end innovation approach? IEEE Eng Manage Rev 48(1):10-13 
Rochford L (1991) Generating and screening new products ideas. Ind Mark Manage 20:287-296

Rogers EM (2010) Diffusion of innovations. Simon and Schuster

Roos J (1996) Distinction making and pattern recognition in management. Eur Manag J 14:590-595

Rosenthal SR, Capper M (2006) Ethnographies in the front end: designing for enhanced customer experiences. J Prod Innov Manag 23:215-237

Salerno MS, de Vasconcelos Gomes LA, da Silva DO, Bagno RB, Freitas SLTU (2015) Innovation processes: Which process for which project? Technovation 35:59-70

Sandmeier P, Jamali N, Kobe C, Enkel E, Gassmann O, Meier M (2004) Towards a structured and integrative front-end of product innovation. In: proceedings of the R\&D management conference (RADMA), ETH-Zürich.

Seidel VP (2007) Concept shifting and the radical product development process. J Prod Innov Manag 24:522-533

Shinno H, Ito Y, Hashizume H (1991) A decision-making methodology for basic layout design of machine tools. JSME Internat J Vib Control Eng Industry 34:290-294

Shinno H, Ito Y, Tadano H (1994) Basic layout design with multiplelayered decision making and transit evaluation. CIRP Ann Manuf Technol 43:111-114

Shpakovsky N (2006) Evolution Trees. Analysis of technical information and generation of new ideas. ISBN 4:5-9348

Simms CD (2012) An analysis of the management of packaging within new product development: an investigation in the UK food and drinks sectors. University of Portsmouth

Slack N, Chambers S, Johnston R (2010) Operations management. Pearson Educ 1:10-34

Soukhoroukova A, Spann M, Skiera B (2012) Sourcing, filtering, and evaluating new product ideas: an empirical exploration of the performance of idea markets. J Prod Innov Manag 29:100-112

Sperry R, Jetter A (2009) Theoretical framework for managing the front end of innovation under uncertainty. In: management of engineering \& technology, 2009. PICMET 2009. Portland international conference on 2009. IEEE, pp 2021-2028.

Stevens GA, Burley J (2003) Piloting the rocket of radical innovation. Res Technol Manag 46:16-25

Stringer R (2000) How to manage radical innovation. Calif Manage Rev 42:70-88

Takey SM, Carvalho MM (2016) Fuzzy front end of systemic innovations: a conceptual framework based on a systematic literature review. Technol Forecast Soc Chang 111:97-109

Talke K, Salomo S, Mensel N (2006) A competence-based model of initiatives for innovations. Creativity Innov Manag 15:373-384

Tatikonda MV, Rosenthal SR (2000) Successful execution of product development projects: balancing firmness and flexibility in the innovation process. J Oper Manag 18:401-425

Thanasopon B, Papadopoulos T, Vidgen R (2016) The role of openness in the fuzzy front-end of service innovation. Technovation 47:32-46

Thomke S, Fujimoto T (2000) The effect of "front-loading" problemsolving on product development performance. J Prod Innov Manag 17:128-142

Thomke S, Von Hippel E, Franke R (1998) Modes of experimentation: an innovation process - and competitive-variable. Res Policy $27: 315-332$

Tidd J, Bessant J, Pavitt K (2005) Managing innovation integrating technological, market and organizational change. John Wiley and Sons Ltd

Trott P (2008) Innovation management and new product development. Pearson Educ 7:10-34
Tzortzopoulos P, Cooper R, Chan P, Kagioglou M (2006) Clients' activities at the design front-end. Des Stud 27:657-683

Unger D, Eppinger S (2011) Improving product development process design: a method for managing information flows, risks, and iterations. J Eng Des 22:689-699

Usher AP (2013) A history of mechanical inventions. Courier Corporation

van Aken JE (2005) Valid knowledge for the professional design of large and complex design processes. Des Stud 26:379-404. https://doi.org/10.1016/j.destud.2004.11.004

van Boeijen A et al (2014) Delft design guide: Design methods. BIS Publishers

Verganti R (2008) Design, meanings, and radical innovation: a metamodel and a research agenda. J Prod Innov Manag 25:436-456

Verganti R (2011) Radical design and technology epiphanies: a new focus for research on design management. J Prod Innov Manag 28:384-388

Verworn B, Herstatt C (2003) A causal model of the impact of the "fuzzy front end" on the success of new product development. In: proceedings of the 10th international product development management conference, Brussels. pp 1159-1175.

Verworn B, Herstatt C, Nagahira A (2008) The fuzzy front end of Japanese new product development projects: impact on success and differences between incremental and radical projects. R\&D Management 38:1-19

Veryzer RW (2005) The roles of marketing and industrial design in discontinuous new product development. J Prod Innov Manag 22:22-41

Williams MA, Kochhar A, Tennant C (2007) An object-oriented reference model of the fuzzy front end of the new product introduction process. Internat J Adv Manuf Technol 34:826-841

Wormald PW (2011) Positioning industrial design students to operate at the 'fuzzy front end': investigating a new arena of university design education. Int J Technol Des Educ 21:425-447

Wowak KD, Craighead CW, Ketchen DJ, Hult GTM (2016) Toward a "theoretical toolbox" for the supplier-enabled fuzzy front end of the new product development process. J Supply Chain Manag 52:66-81

Wynn D, Clarkson J (2018) Process models in design and development. Res Eng Design 29:161-202. https://doi.org/10.1007/ s00163-017-0262-7

Yoon BS, Jetter AJ (2015) Connecting customers with engineers for the successful fuzzy front end: requirements of tools. In: management of engineering and technology (PICMET), Portland international conference on, 2015. IEEE, pp 1585-1595.

Yu FZ, Chen J, Shen HH (2006) Idea management model for NPD fuzzy front end: empirical analysis based on all-key-elements innovation in TIM. Chinese J Manag 3:573-579

Zhang Q, Doll WJ (2001) The fuzzy front end and success of new product development: a causal model. Eur J Innov Manag 4:95-112

Zhang Q, Vonderembse MA, Cao M (2009) Product concept and prototype flexibility in manufacturing: implications for customer satisfaction. Eur J Oper Res 194:143-154

Ziv-Av A, Reich Y (2005) SOS-subjective objective system for generating optimal product concepts. Des Stud 26:509-533

Publisher's Note Springer Nature remains neutral with regard to jurisdictional claims in published maps and institutional affiliations. 